\title{
A COMPUTER-AIDED METHOD \\ FOR ANALYSIS OF SNOP-CODED \\ HISTOPATHOLOGY OBSERVATIONS
}

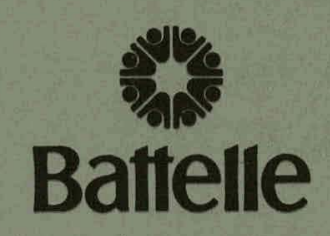

Pacific Northwest Laboratories

Richand, Wiahington 9935:

SEPTEMBER 1974

Prepared for the U.S. Atomic Energy

Commission under Contract AT(45-1):1830 


\section{DISCLAIMER}

This report was prepared as an account of work sponsored by an agency of the United States Government. Neither the United States Government nor any agency Thereof, nor any of their employees, makes any warranty, express or implied, or assumes any legal liability or responsibility for the accuracy, completeness, or usefulness of any information, apparatus, product, or process disclosed, or represents that its use would not infringe privately owned rights. Reference herein to any specific commercial product, process, or service by trade name, trademark, manufacturer, or otherwise does not necessarily constitute or imply its endorsement, recommendation, or favoring by the United States Government or any agency thereof. The views and opinions of authors expressed herein do not necessarily state or reflect those of the United States Government or any agency thereof. 


\section{DISCLAIMER}

Portions of this document may be illegible in electronic image products. Images are produced from the best available original document. 
NOTICE

The report was prepared as an account of work sponsored by the United States Government. Neither the United States nor the United States Atomic Energy Commission, nor any of their employees, nor any of their contractors, subcontractors, or their employees, makes any warranty, express or implied, or assumes any legal liability or responsibility for the accuracy, completeness or usefulness of any information, apparatus, product or process disclosed, or represents that its use would not infringe privately owned rights.

\title{
PACIFIC NORTHWEST LABORATORY operated by BATTELLE \\ for the \\ U.S. ATOMIC ENERGY COMMISSION Under Contract AT(45-1)-1830
}

\author{
Printed in the United States of America \\ Available from \\ National Technical Information Service \\ U.S. Department of Commerce \\ 5285 Port Royal Road \\ Springfield, Virginia 22151 \\ Price: Printed Copy $\$ 5.45$; Microfiche $\$ 1.45$
}


A COMPUTER-AIDED METHOD FOR ANALYSIS

OF SNOP-CODED HISTOPATHOLOGY OBSERVATIONS

R. J. 01son, Biology Department

C. R. Watson, Systems Department

\section{Battelle}

Pacific Northwest Laboratories

Richland, WA 99352

September 1974

This paper is based on work supported by the United States Atomic Energy Commission under Contract AT(45-1)-1830.

This report was prepared as an account of work sponsored by the United States Government. Neither the United States nor the United States Energy Research and Development Administration, nor any of their employees, nor any of their contractors, subcontractors, or their employees, makes any warranty, express or implied, or assumes any legal liability or responsibility for the accuracy, completeness or usefulness of any information, apparatus, product or process disclosed, or represents that its use would not infringe privately owned rights. 


\section{TABLE OF CONTENTS}

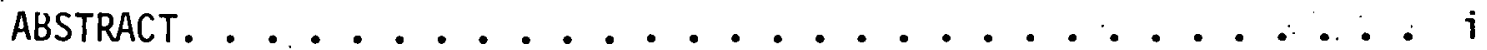
INTRODUCTION. .....................

Goals of System................ 2

General Data System. .............. 3

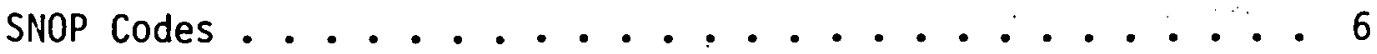

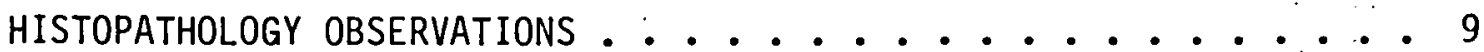

SNOP Coding, Grading, and Remarks........... 9

SNOP Coding Tumors ................ 12

Condensing Coded Records .............. 13

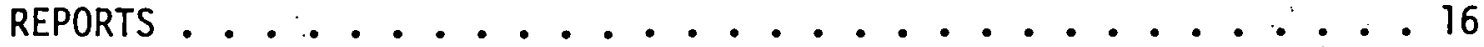

Case Histories ...................... 16

List of Observations for Editing ........... . . 21

Treatment Group Summaries. . . . . . . . . . 25

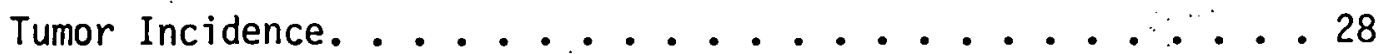

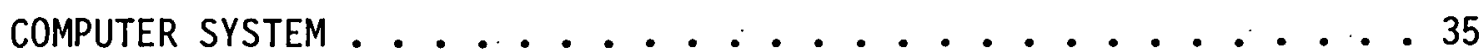

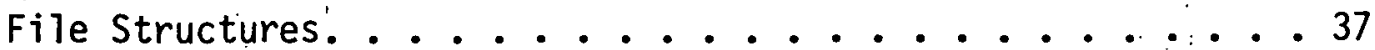

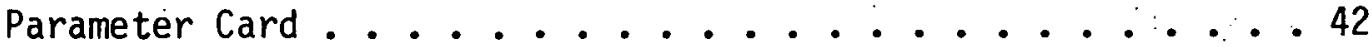

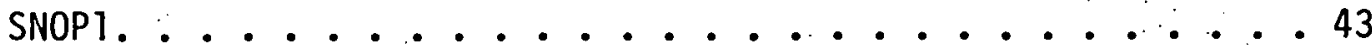

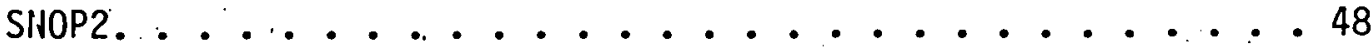

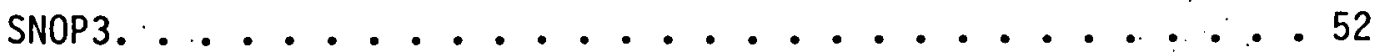

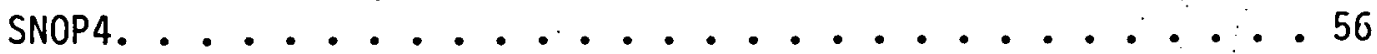

SNOP5/SNOPG. ................. 60

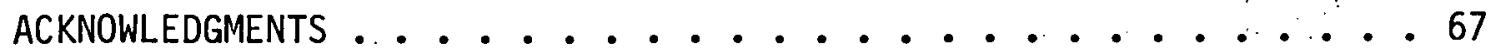

APPENDIX A Program Listings (Microfiche) ........... A-1 


\section{LIST OF FIGURES}

Figure

Pàge

Overall Data Handling Scheme . . . . . $\because . .44$

SNOP Coding Form . . . . . . . . ..... 10

SNOP Code Equivalents Form . . . . . . . . 15

Case History For Hypothetical Animal 100 (SNOP1) . . • 17

Error Report (SNOPI) ............. 19

Tumor Report (SNOPI) . . . . . . . . . . 20 Cross-Reference Table (SNOP2)........... 23

Table of Animals With-Specific Lesions (SNOP2) . . • . 24

10 Detailed Lesion Incidence and Grades By Treatment Group (SNOP3).................... 27 :

11 Summary of Lesion Incidence And Severity By Treatment

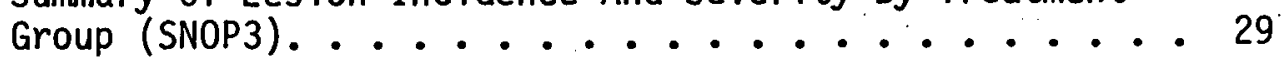

12 : Tumor Incidence Report (SNOP4) . . . . . . . . 30

13 Tumor Incidence Summary Table (SNOP4). . . . : 32

14. Tumor Incidence Treatment Group Comparison (SNOP4) • . 33

15 Grand Totals of Tumor Incidence (SNOP4) . . . . . . 34

16 Flowchart of system. . . . . . . . 36

17 SNOP Dictionary Characteristics. . . . . . 38

18 HT Input And IDNTXXX File Characteristics. . . . . . 40

19 SNOPXXX And TUMRXXX File Characteristics ...... 41

20 Parameter Card ........................... 42

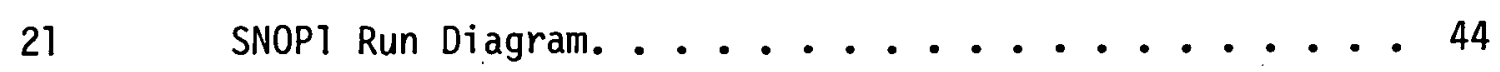

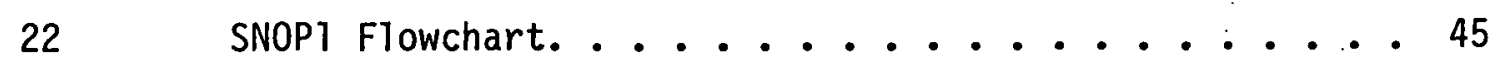


Figure

Page

23

24

25

26

27

28

29

30

31

SNOP1 Program Abstract. ........... 46

SNOP2 Run Diagram ................. 49

SNOP2 Flowchart ............ 50

SNOP2 Program Abstract. ........... 51

SNOP3 Run Diagram ........... 53

SNOP3 Flowchart ................... 54

SNOP3 Program Abstract. .......... 55

SNOP4 Run Diagram ............. 57

SNOP4 Flowchart ............. 58

SNOP4: Program Abstract. ............. 59

SNOP5/SNOP6 Run Diagram ............. 61

SNOP5" Flowchart .................. 62

SNOP6 Flowchart ........... 63

SNOP5 Program Abstract............. 64

SNOP6 Program Abstract. . . . . . . . . 65 
A Computer-Aided Method of Analys is

Of SNOP Coded Histopathology Observations

R. J. 01 son, Biology Department

C. R. Watson, Systems Department

Battelle

Pacific Northwest Laboratories

Richland, WA 99352

\section{ABSTRACT}

A series of FORTRAN computer programs, running on a CDC-CYBER computer, aid investigators in analysis of histopathology observations of research animals. Clinical and pathologic observations are coded, utilizing the Systemztized Nomenclature of Pathology (College of American Pathologists, Chicago, IL, 1965). The first programs sort, uncode, and print them while checking for several types of errors. After the investigator edits these preliminary reports, the second programs print several tables of lesion incidence by treatment group; including a series summarizing neoplastic lesions. Included in this document are instructions for use of the programs, flowcharts, and a microfiche containing detailed FORTRAN. code listings.

This paper is based on work supported by the United States Atomic Energy Commission under Contract AT(45-1)-1830. 


\author{
A COMPUTER-AIDED METHOD OF ANALYSIS \\ OF SNOP CODED HISTOPATHOLOGY OBSERVATIONS
}

\title{
INTRODUCTION
}

This document describes several computer programs which aid in the analysis of histopathology observations by tabulating the incidence of various lesions in groups of laboratory animals. These programs are based on the Systematized Nomenclature of Pathology (SNOP) dictionary developed by the College of American Pathologists (Chicago, IL, 1965). The pathologist and/or the investigator reduces clinical, gross necropsy, or microscopic observations to a ten-character code defining the anatomical location; the condition observed, and the severity. The computer programs, running on the CYBER-70 computer, operated by Computer Sciences Corp., Richland, Wash., translate SNOP coded observations for proofreading and editing, then process the data to form several tabular reports. The system is especially useful in studies involving large numbers of animals, or in long-term studies in which the volume of narrative pathology reports is accumulated as each animai dies.

The first sections of this report are oriented to biologists, while the last part presents computer program details. Throughout this report we assume that the reader has access to the SNOP dictionary and we have limited our discussion of. SNOP to aspects peculiar to our system. We intend that the computer programs continue to evolve in response to user needs and encourage the reader to suggest modifications or additions which will increase their value. 
GOALS OF SYSTEM

The primary goal of the system is to provide an efficient aid in the analysis of histopathology results from research studies involving large numbers of animals. It is expected that investigators with only a few dozen animals per study will continue to tabulate results manually. The computer programs are designed to simplify the tabulation process, not to produce final tables for publication. The investigator must make judgments about which findings are significant and about the degree of condensation of diagnosis terms desirable for a specific study.

A secondary goal is to provide a data base which pools observations of various studies by various investigators which will allow better definition of spontaneous lesions in animal populations. A standard terminology with common definitions is desirable so that inter-study and inter-species comparisons may be made.

A future goal is to routinely tabulate gross findings at necropsy with the microscopic observations. We have designed and tested the SNOP system to handle gross observations. However, these records are not yet routinely collected because we plan to use them in our yet-to-be-completed Tissue inventory system. When this system is operational, we will capture both the tissue identification for inventory purposes and the SNOP code describing why the tissue was sectioned. This will allow a cross-reference between accession numbers assigned by the tissue preparation laboratory and animal identification numbers. It will also add a dimension of quality control in that obvious mis-matches between gross and microscopic SNOP coded diagnoses will encourage re-examination of the tissues in question. 
Until these goals are implemented, it will continue to be the investigator's responsibility to confirm that gross and microscopic observations agree as a check on animal number/slide number correlation.

\section{GENERAL DATA SYSTEM}

The two Life Sciences Departments, Biology and Ecosystems utilized the Systems Department for guidance in statistical and data processing areas of research projects. A Biometrics Center, staffed by the Systems Department, is located in the Life Sciences Complex. The Center facilitates research by providing consultation about experimental design and statistical techniques and by analyzing experimental results when requested. In addition, the Biometrics Center provides systems analysis and data processing services.

The SNOP system described in this document is primarily a data processing technique. Statistical interpretation of the tabular computer output is a necessary step in drawing meaningful conclusions from experiments. The procedures employed and the form of this interpretation depend on the nature of the research and will vary from experiment to experiment as the investigator and statistician work together.

When a research effort involves a large number of animals it is usually conducted by a multi-disciplinary, multi-department team of investigators. The data analyst is an essential member of this group as shown in Figure 1. Frequent interactions between the analyst and other members of the team helps to avoid costly duplication of data recording and handling through.: establishment of conventions such as treatment codes to be used throughout the investigation. 


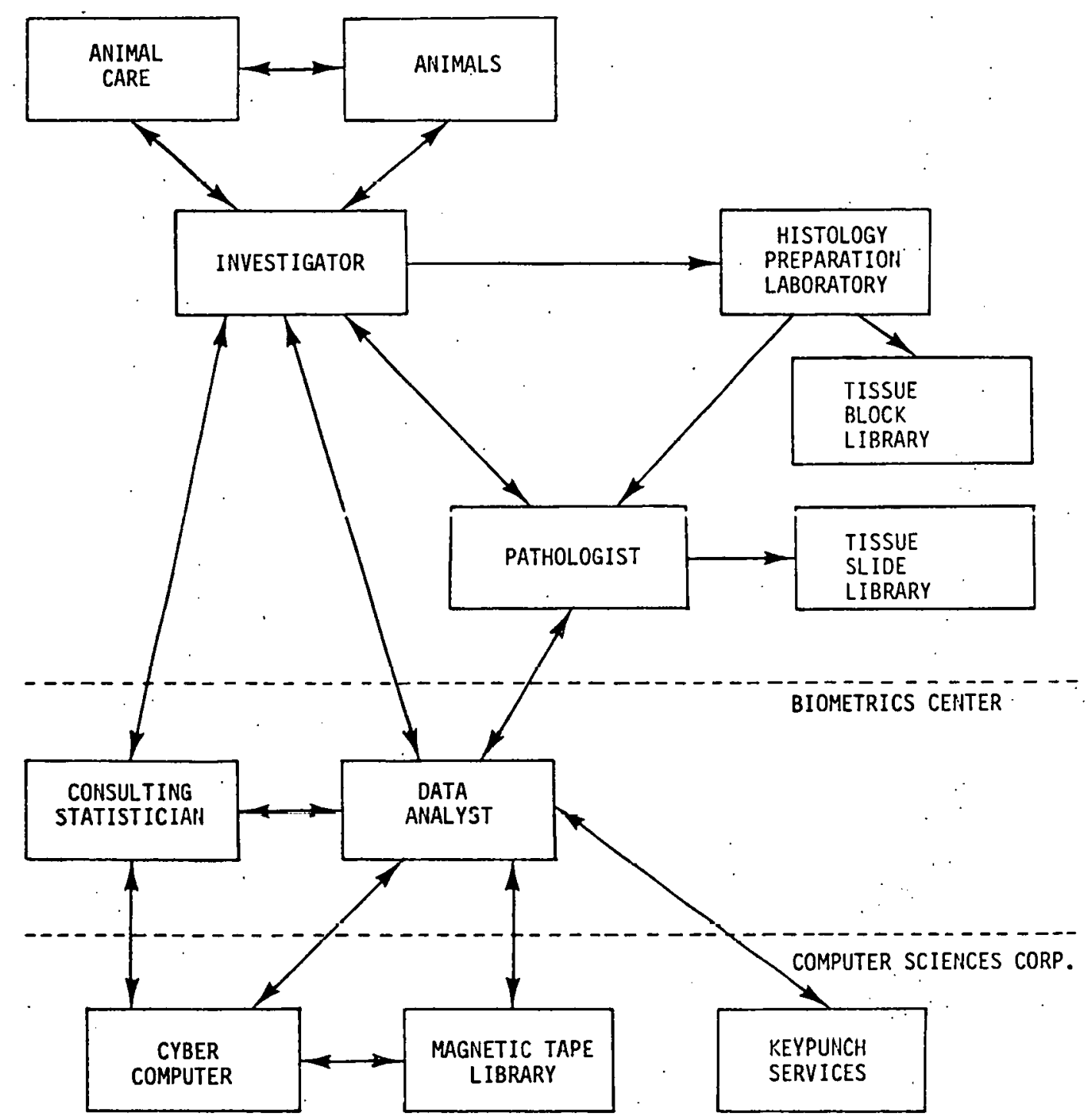

FIGURE 1. Overall Data Handling Scheme 
The flow of information in a typical study follows this course of events. First, the investigator and statistician establish the experimental protocol, then the animals are given the appropriate treatment and studied for a specified time. At death or sacrifice, the tissues of interest are removed and sectioned. The embedded specimen is stored in the tissue block library, with microscope slides forwarded to the pathologis.t. Eventually the pathologist's observations are reduced to SNOP codes and forwarded to the data analyst. Preliminary computer printed tables of lesion incidence are returned to the pathologist for review. Final tables are used by the investigator in consultation with the statistician to perform tests of significance on those findings relative to the study. Both investigators (or their technicians) and pathologists (or medical secretaries) can contribute data recorded on handwritten forms to the Biometrics Center. Forms are checked for completeness, keypunched and accumulated until processing is requested by the investigator or pathologist. Considerable interaction occurs between the researchers and the data analysts to check for errors and edit the data prior to final analysis. This data checking may be postponed until the final report is needed; however, we encourage submitting and "cleaning up" smaller sets of data as they are produced by the pathologist. The Biometrics Center assumes responsibility to store the data for future reference and analyses. As observations become available on control animals tabulations of spontaneous lesions in the animal populations used at the laboratory will be produced. 
SNOP CODES

The SNOP code system was developed by medical pathologists, and is . not entirely suited for research studies using laboratory animals because of anatomical and procedural differences (e.g., there are no SNOP codes for tail, or euthanasia). However, it is probably the most widely used system, and offers an àready published, standardized, logically structured basis for our necds.

The code is well described in the introduction to the SNOP dictionary. The basic scheme is:

Diseases may be defined in terms of four areas of information: 1) the part of the body affected (Topography); 2) the structural changes produced (Morphology); 3) the etiologic agent (Etiology); and 4) the functional manifestations (Function): This code is divided into four separate, interdependent fields comparable to these areas: Topography, Morphology, Etiology, and Function. Within a field, terms are assigned a four-digit number. The first (left hand) digit indicates the section of the field, the other numbers indicate progressively finer subdivisions. These groupings reflect, as far as possible, natural relations. (page xiv, SNOP dictionary).

We have expanded the SNOP code system by adding two characters: a qualifier code to rank the grade or severity of lesions - l (very slight) to 5 (severe); and a code to indicate whether the observation was made while the animal was alive (clinical), at necropsy (gross), or microscopically (micro). We have also allowed space for the observer to qualify his coded observations with remarks.

As we become more experienced with the codes, and as the need arises, we expect to modify the SNOP code dictionary itself by adding codes required by our biology research needs. 
One of the difficulties encountered in developing a computer scheme for decoding SNOP codes at a reasonable cost was the multiplicity of definitions and synonyms listed in the SNOP dictionary. We made some rather arbitrary but necessary decisions about this problem. First, we decided that none of the synonyms would be stored in our computerized dictionary; the computer will print the English phrase adjacent to the four-digit code in the SNOP dictionary.

The second decision, possibly harder to live with, concerned the fact that the SNOP code scheme allows for several types of "site-specific" lesions such as bronchopneumonia or appendicitis. The SNOP dictionary indicates that appendicitis should be coded T6600 for the appendix and M4001 for inflammation and that the resulting combination will be translated as appendicitis. Similarly, bronchopneumonia should be coded T2800 for the lung and M4001 for inflammation, with the resulting site-specific combination translating as bronchopneumonia. Unfortunately, it is very expensive for smart computer programmers to instruct the not-so-smart computer to do this. We elected to use the more general code, i.e. M4000, and print such lesion descriptions as "lung, inflammation" or "appendix, inflammation", while fully aware that there are more appropriate descriptive terms. Using the site-specific code M4001 will result in both lesions being described as "appendicitis".

When discrepancy exists between the term printed next to the SNOP code in the dictionary and the term desired by the pathologist, we recommend and encourage entering the desired term in the remarks. That is, if a site-specific lesion is being described, or a synonym is preferred, 
or the proper term does not exist in the dictionary, he should select the closest code and enter what he really means in the remarks. 


\section{HISTOPATHOLOGY OBSERVATIONS}

We have attempted to develop a flexible system to record observations without imposing rigid rules. Although we intend to expand the system to include information obtained at necropsy, our current efforts are concentrated on obtaining the results from the pathologist!'s examination of slides. Our experience indicates that most pathologists prefer to write or dictate narrative findings about the slides as they examine them. This typed narrative subsequently becomes the basis for the pathologist, medical secretary or investigator to perform the SNOP coding. The slides remain the primary "record" and the narrative and/or codes may be subject to change based on re-examination of the slides.

Clinical findings in the live animal and gross observations at necropsy can also be SNOP coded for tabulation. As with the microscopic findings, these would probably be abstracted from animal records. However, after becoming familiar with the coding, observers may develop a shorthand format for their narrative to facilitate coding. Obviously, recording anatomical location, diagnosis and severity grade, in that order, would save time. A preprinted list of the tissues to be examined would also save time and insure completeness.

CODING, GRADING, REMARKS

The form for recording the SNOP codes is presented in Figure 2. The genera1 procedure for using the SNOP dictionary to code topographic site and diagnosis for each lesion is straightforward. The conventions outlined in Table I insure consistency within and among investigations. 


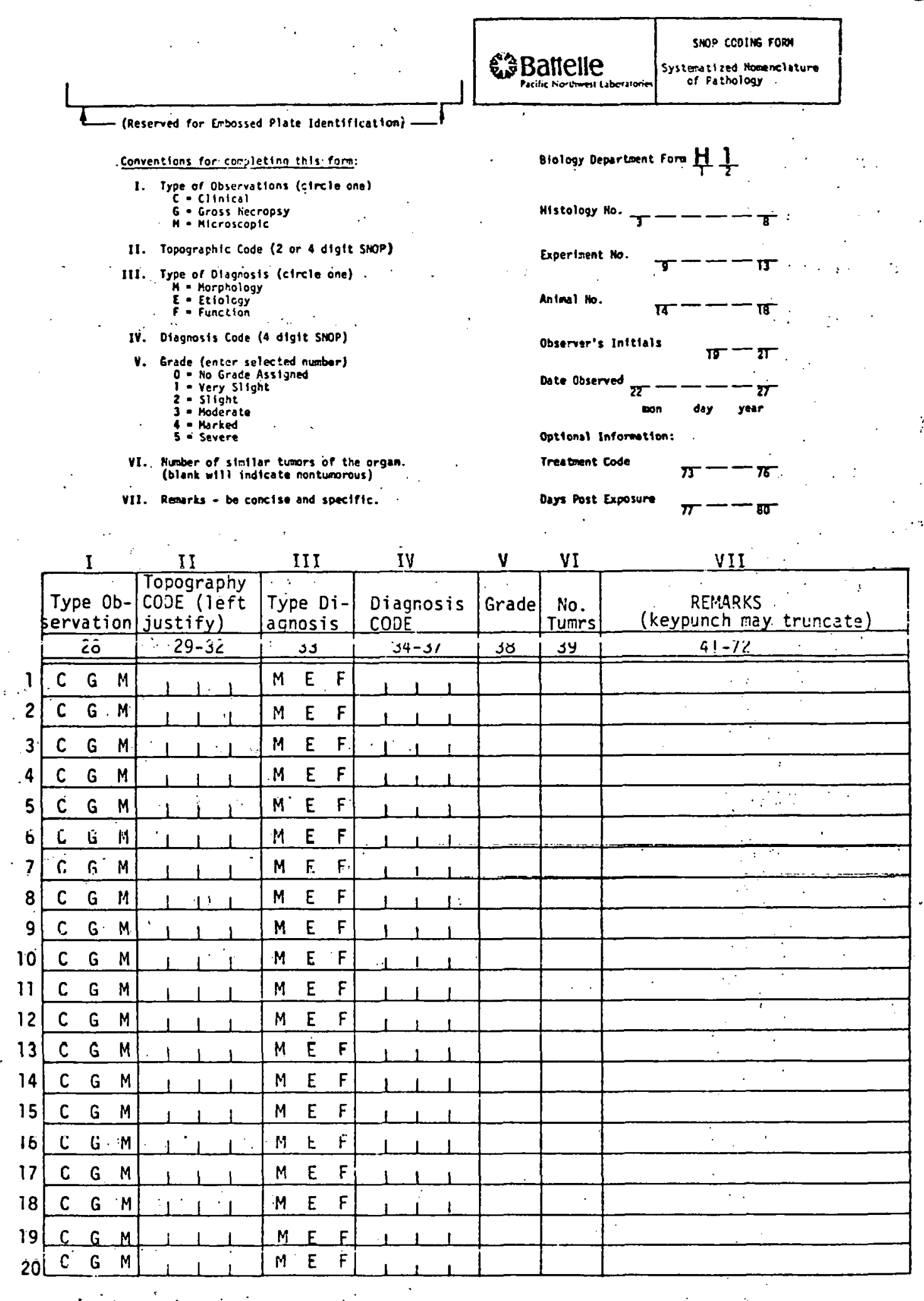

\section{FIGURE 2. SNOP Coding Form}


Table I

Conventions For Completing SNOP Coding Form

Histology No.

Expt. Identification

Animal Identification

Observer's Initials

Date Observed

Type Observation

Topography Code

Type Diagnosis

Diagnosis Code

Grade

Number of tumors

\section{Remarks}

Treatment Code

Days Postexposure
Important for cross-referencing to slides.

Required in connection with animal number to have unique identification.

Up to five numbers, right adjusted.

Pathologist doing narrative or coding.

Date slides read, or, if clinical observation, date animal observed.

C - Clinicai

G - Gross

M - Microscopic

(Circle appropriate letter)

Requires either 2- or 4-digit SNOP code.

Circle letter indicating type of diagnosis code entered from SNOP dictionary. M - Morphology

E - Etiology

F - Function

Required 4-digit SNOP code. If normal observation, usually a MOOOI is entered.

Required for all gross and microscopic diagllus is uniess nurlliai ur iunur iesiuns.
0 - No grade
3 - Moderate
1 - Very slight
4 - Marked
2 - Slight
5 - Severe

Required if tumor lesion (M8000. to M9999) is observed. This indicates the number of discrete tumors or nodules of similar type within the specified organ. " 9 " indicates multiple tumors such as in a metastatic tumor.

Used to clarify SNOP code; used especially with site-specific lesions.

Currently used as 4-character code to indicate experimentai treatment group. Eventually this may be routinely available from the computer. data banks of animal inventory.

Entered as right adjusted 4-digit number indicating age postexposure. . This also may be routinely available in the future from within the computer. 
SNOP CODING TUMORS

If the investigator consistently follows the conventions for completing the SNOP coding form, a minimum of error correction will be necessary prior to analysis of the experiment. However, recording the presence of a neoplastic lesion requires additional conventions to ensure that the tumor incidence tables allow meaningful comparison between treatment groups. The first of these guidelines is related to the last dlyit or the SNOP morphology code. As outlined on page xv of the SNOP dictionary, this digit is used to indicate the condition of the tumor. We have condensed these conditions into three categories: benign, malignant, and metastatic.

- Benign tumors (codes 0 or 1 ) - there is no logical restriction on the number of benign tumors which may be reported for each animal.

- Malignant tumors, primary site (codes 2,3,4 or 5) - if an animal exhibits malignancy, the system expects that there is at least one primary site. If the primary site is unknown, or if the lesion is diffusse, as in leukemia, enter T0001 (site unknown) as the location of the primary malignant lesion.

- Malignant tumors, secondary site (codes $6,7,8$ or 9) - the system expects animals exhibiting metastatic tumors to have at least one primary site also. If not, the animal will not be included in the proper table of incidence (use T0000 if primary site is unknown).

- More than one primary tumor - the system has no method of differentiating hetween legitimate and erroneous records of an animal with more than one primary malignancy. It is credible for an animal to have a lung tumor and an osteosarcoma, which would be recorded as two tumors in the incidence summaries. However, records showing a carcinoma of the liver and also of the spleen probably refer to only one tumor. A. proof-reading table of tumors is provided to help the investigator resolve these possible errors. 
The second convention we have established in regard to recording tumors is the addition of a code for the number of tumors in a given tissue. If several nodules of the same tumor are recorded, the count might reflect a rather advanced tumor state. The code ranges from 1 to 9 , with any number greater than 9 entered as 9 . The editing and proofreading programs of the system check to see if the number of tumors agrees with the diagnosis. That is, it is "illegal" to record a number of tumors without a morphology code in the tumor series (M8000 and M9999). Similarly, it is "illegal" to enter a tumor morphology code without a valid number of tumors.

\section{CONDENSING CODED RECORDS}

Narrative descriptions and SNOP codes allow seemingly $i$ imitless lesion categories, however the goal of analyzing research results is to reduce the findings to a manageable number of categories. The SNOP topography codes are structured to allow general or specific site descriptions by using two or four digits of the code. Even though all four digits are recorded, the computer programs can group sites by the first two digits. This is not entirely satisfactority as some 2-digit codes are equivalent (both T01 and T02 are 2-digit codes for the skin). We have therefore developed the ability to consider various codes equivalent for summarizing purposes while preserving the original specific codes.

Condensing diagnosis codes ( $M, E$, or $F$ series) into general categories is performed by the pathologist. By examining the detailed listings of lesions, he or she can make decisions as to which diagnoses are biologically equivalent so as to allow pooling of differently SNOP coded lesions. 
Probably very few conventions can be established, as each experimental study will have different criteria for combining the somewhat artificial subdivisions imposed on the data by the coding.

The pathologist can inspect the initial computer listings and select codes to combine for the final analysis. The form presented in Figure 3 is used to define equivalent codes. Once the data is edited, the summary programs are run for the final analysis. 


\begin{tabular}{|c|c|}
\hline SNOP CODE EQUIVALENTS \\
\hline
\end{tabular}

Observer

Date

Expt. No.

Species

Original SNOP codes may be temporarily altered for summary reports. This form allows you to define more general codes to be equivalent to one or several more specific codes. Records may also be dropped using the "DROP" code.

- Topography Codes

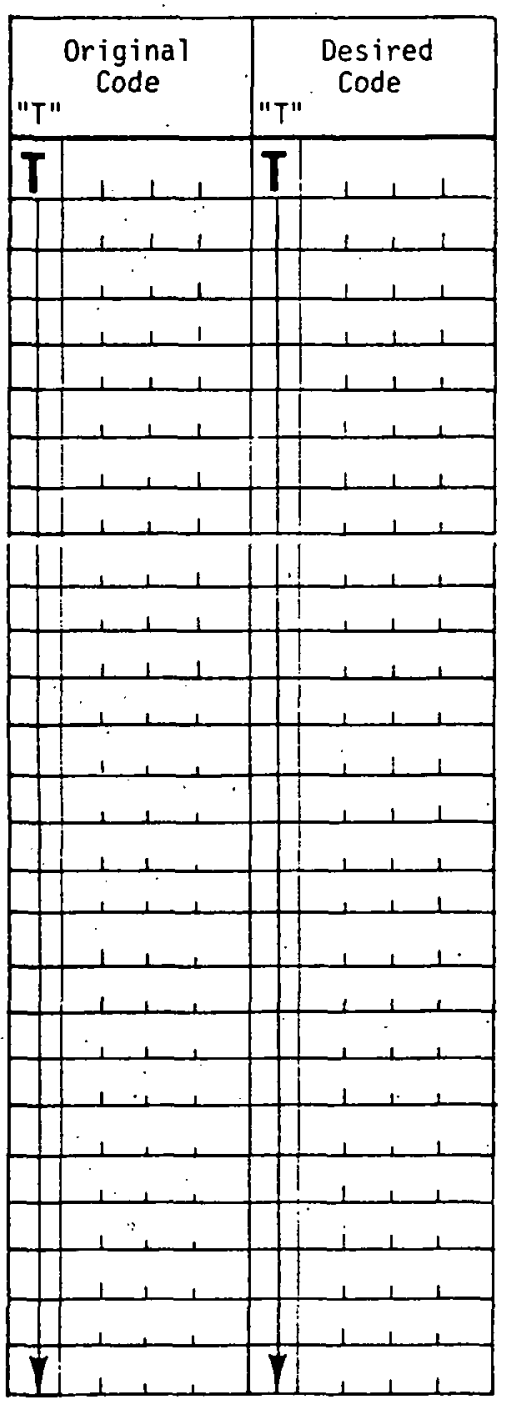

Diagnoses Codes

\begin{tabular}{|c|c|c|}
\hline $\begin{array}{l}\text { Original } \\
\text { Code } \\
\text { "E, } F, \mathbb{M} \text { " }\end{array}$ & $\begin{array}{l}\text { Optional } \\
\text { Topography } \\
\text { Qualifier }\end{array}$ & $\begin{array}{l}\text { Desired } \\
\text { Code } \\
\text { "E,F,M" }\end{array}$ \\
\hline$\cdot \begin{array}{lll}1 & 1 & 1\end{array}$ & 111 & 1 \\
\hline 111 & $1 \quad 1$ & 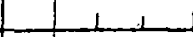 \\
\hline 111 & 1 & $\perp$ \\
\hline 111 & & 1. \\
\hline 111 & 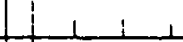 & 1 \\
\hline 1 & 1 & 1 \\
\hline $1 \quad 1 \quad 1 \quad$ & -1 & $\therefore 1$. \\
\hline$\perp \quad 1$. & $1 . . .1$ & 1 \\
\hline 1 & 1 & 1 \\
\hline 11 & 1 & $\perp$ \\
\hline 1,1 & & i \\
\hline & 1 & 1. \\
\hline لـ & 1 & i \\
\hline 1 & ـ & $\therefore \quad \therefore$ \\
\hline 1 & & 1 \\
\hline 1 & 1 & $1 \div 1$ \\
\hline 1. & $\perp$ & $i 1$ \\
\hline 1 & 1 & 1 \\
\hline 1 & ـ & 1 \\
\hline 1 & $\perp$ & 1 \\
\hline 11 & & \\
\hline 1 & 1 & $i$ \\
\hline $1 \quad 1$ & 1 & 1 \\
\hline 1,1, & $\cdot$ & $i$ \\
\hline 1 & 1 & 1 \\
\hline 1,1 & 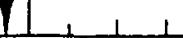 & 1 \\
\hline
\end{tabular}

FIGURE 3. SNOP Code Equivalents Form 


\section{REPORTS}

There are four types of tabulations performed by the system:

- All observations for each animal (case histories)

- All animals for each lesion (1ist of observations)

- Observations in each treatment group (treatment summaries)

- Tumors in each treatment group (tumor incidence).

The first two are used primarily in editing and consolidating the SNOP codes, the last two in analysis of the investigation. Portions of these tabulations may be judiciously used as appendices to published reports. Each type of report is described in detail below.

\section{CASE HISTORIES}

The first computer program, SNOP1, prints reports which tabulate all observations about each individual animal. These case histories are printed one animal per page so that they may be included in the file folder for that animal. An example of a report for hypothetical Animal 100 is shown in Figure 4. After the animal identification, each SNOP coded observation is printed in sequence by date of observation and by anatomical location. Each observation produces a minimum of two printed lines. The first contains the location code and its English equivalent, as well as the severity code and number of tumors, if any. The second line contains the morphology, etiology, or function code associated with that location and its English equivalent. If the investigator qualified his observation with remarks, these appear as a third linc.

Note that this report displays both the SNOP codes and their English equivalents. Subsequent analytical tables are produced according to the 


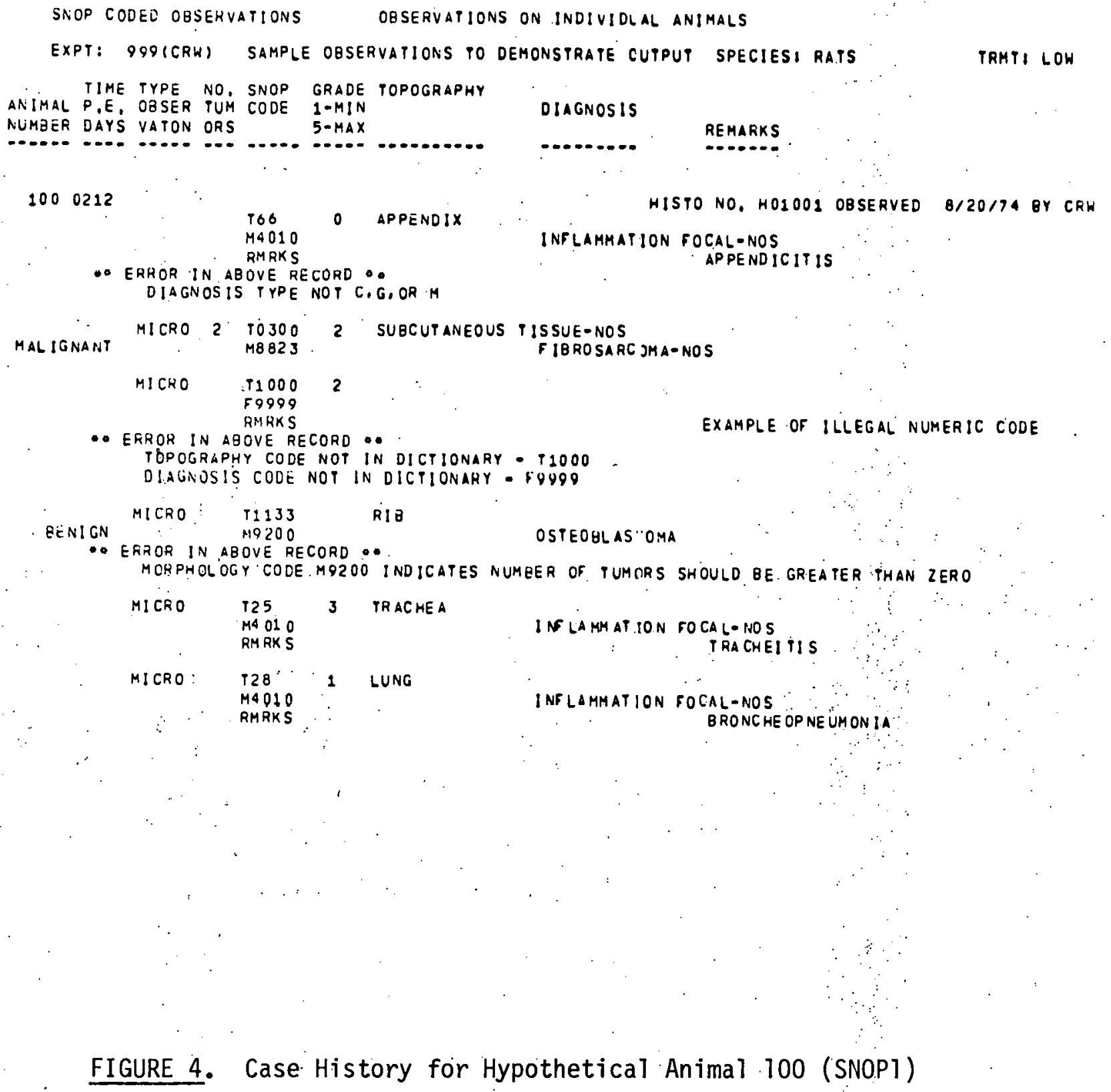


codes, but print only the English translations.

As shown in the example, the computer performs a considerable range of error-checking to help insure that the data conforms to the conventions for input described in Table I. To facilitate proof-reading, these errors messages are also printed in a separate subreport of SNOPI as shown in Figure 5. As an aid to the Biometrics staff, the card containing the crror is printed on the error report so that corrections may be easily annotated.

While this error report helps to insure that each SNOP coded observation is complete and logical, there is no way that the computer can insure that every lesion for each animal enters the system. It remains the investigator's responsibility to see that all pertinent observations are entered, and that the SNOP codes accurately reflect what was observed. The sample case history also shows several tumors observed in this animal. Since many of our studies focus on tumor development, records indicating tumorous lesions are also printed in a subreport (Figure 6), which lists all observations of tumors in a given study. In the proofreading stages of analysis, it is used to help standardize diagnostic terminology throughout the study (e.g., was the lesion coded M8013 "Carcinoma" really different from those coded M8034 "Undifferentiated Carcinoma"). This report provides the only summary which prints all tumorous lesions observed in a given animal (other reports list tumor incidence, but in a summarized form).

The sample tumor report illustrates another computer-performed error checking feature, as shown in the report of Animals 102, 104 and 105. The 


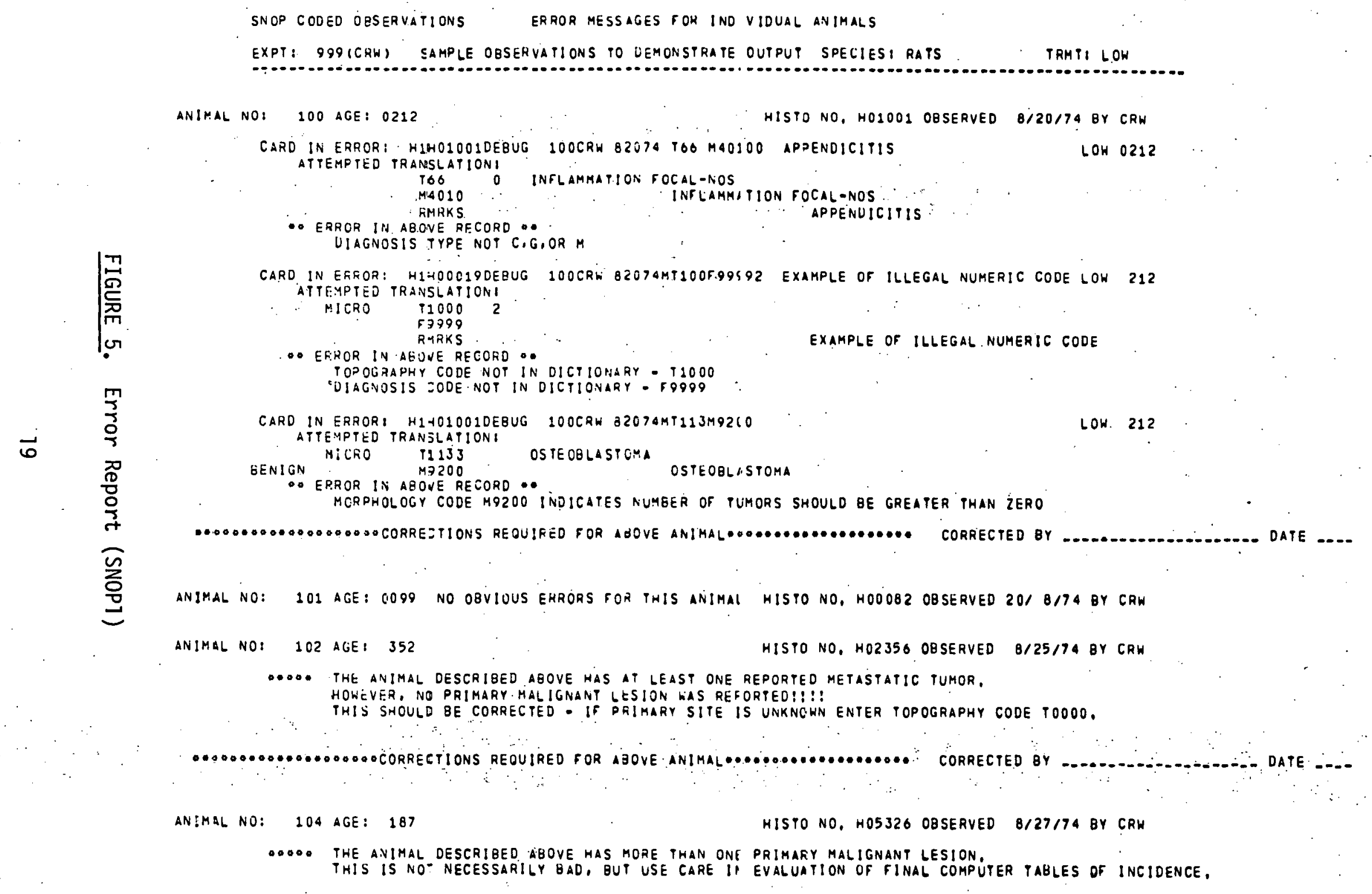




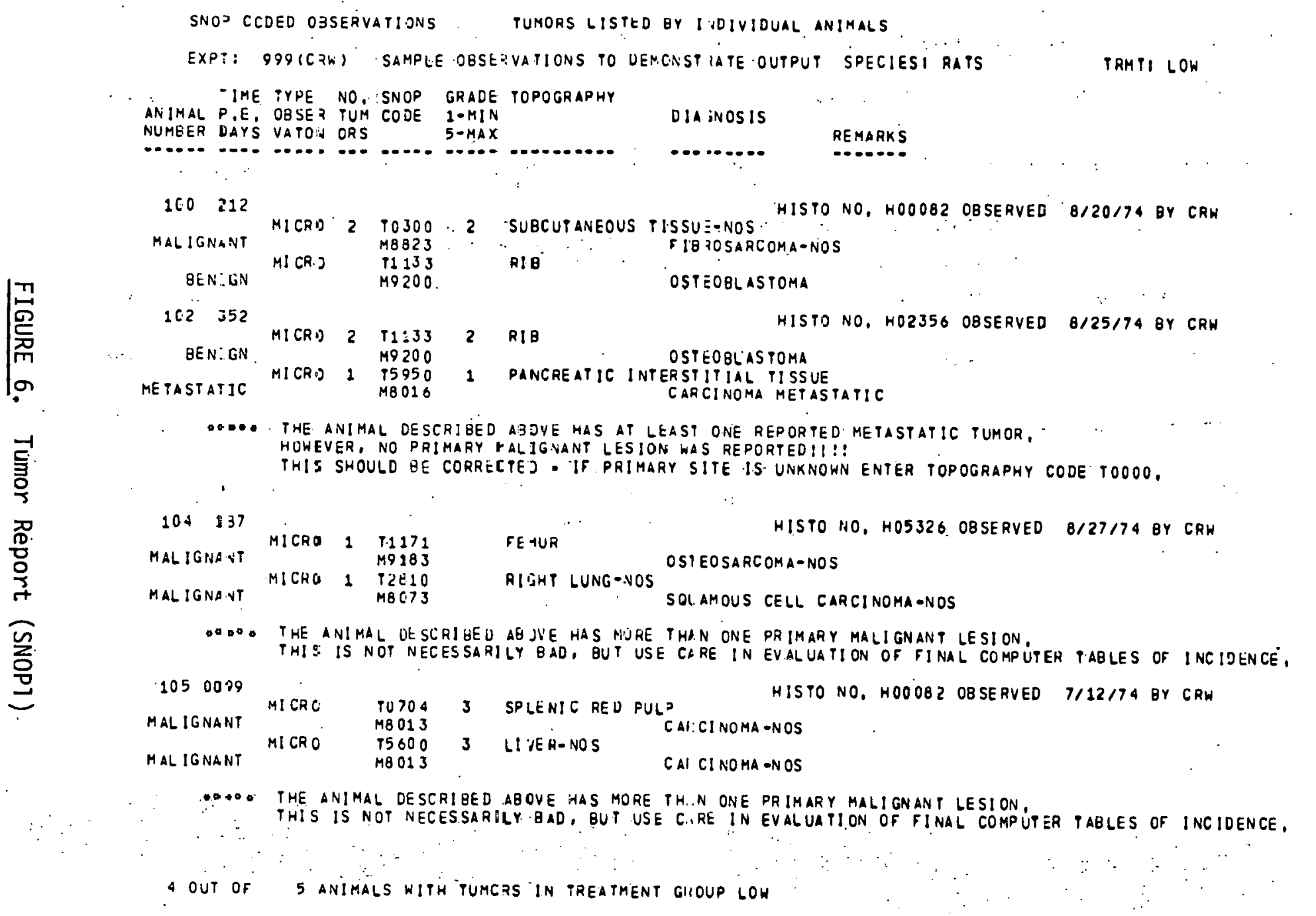


records for Animal 102 indicate that a metastatic lesion was observed, al though no record of a primary lesion was entered. Since this is illogical, the tissues should be re-examined or an entry of T0001 (body, general, no specific site, or site unknown) and the appropriate lesion code should be entered.

Animals 104 and 105 present another possible inconsistency: two primary tumors are reported, and the computer has no way of knowing whether this is logical. Animal 104 did, in fact, have a bone tumor in the leg and a lung tumor, but Animal 105 illustrates an error which would invalidate tables of tumor incidence. It is probably not true that there were two primary abdominal carcinomas in Animal 105. The tissues should therefore be re-examined to see if the tumor originated in the liver or the spleen.

These three reports printed by SNOPI are usually produced several times in the course of analysis of a study. The first few times they are used for proof-reading and editing, the final copy may be filed with other records for each animal. We also have the capability of producing microfiche copies of the final report for permanent, less voluminous storage.

\section{LIST OF OBSERVATIONS FOR EDITING}

The second type of report used in proof-reading is the inverse of the case history report. Whereas SNOPI lists all observations for a given animal, SNOP2 lists all animals in which a given observation is seen. We have used.several techniques to condense this report to 
manageable size: we first print a cross-reference table of animal identification, survival time and histology number as illustrated by Figure 7 .

The cross-reference table permits us to refer to animals simply by their numbers in the main table, although an investigator may need the Histology Number to re-examine the slide. To further condense the main table of SNOP2; (Figure 8), records of normal conditions are omitted, and. only the first two digits of the location code are considered unique; i.e., a reported observation of inflammation of the left 1 ung (T2850) is combined with those reporting simply inflammation of the lung (T28).

The table is arranged in the same order as the SNOP dictionary, with topography code the major subdivision. Within each topography code (2-digit only), the etiology, function, and morphology codes are presented in numerical order. To aid in proof-reading, the actual SNOP codes are printed at the extreme right of the table.

The table is used for two primary purposes: (1) to detect miscoded observations, (for example, If atrophy of the thymus is listed, and it is known that thymus examination was not in the protocol, al] the SNOP. codes for that animal are suspect); (2) to aid in condensing the records; (e.g., if observations for the lung include "inflammation, NOS" in five animals, and "inflammation, diffuse, NOS" in three animals, and "inflammation, acute, focal" in another, one might wish to classify all nine animals as "inflammation, NOS"). One.could change the records either permanently or temporarily to do this. The latter method is discussed in the "Condensing Coded Records" section of this publication (page 13). 


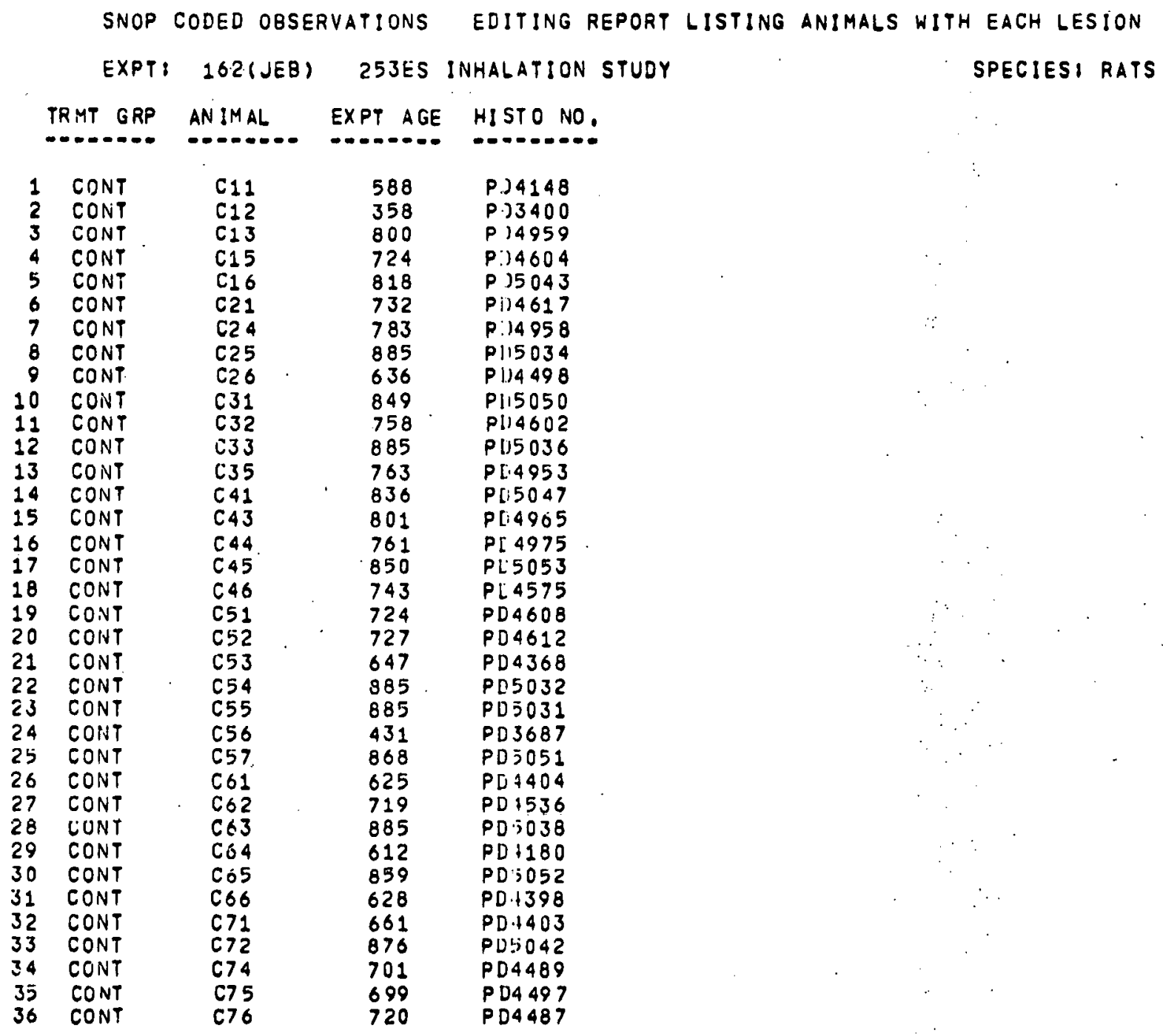

FIGURE 7. Cross-Reference Table (SNOP2) 
SAOP CODEE OESERVATIONS EDITING FEPORT LISTING ANIMALS HITH EACH LESION

\begin{tabular}{|c|c|}
\hline 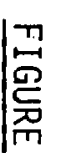 & $\begin{array}{l}\text { EXPT: ISZ(JEB) 25JES INHALATION } \\
\text { LOCATICHS ANJ DIAGNOSES }\end{array}$ \\
\hline$\infty$ & 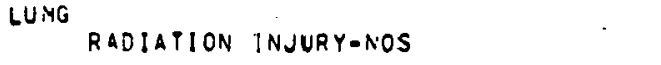 \\
\hline$\underset{D}{\vec{\sigma}}$ & $\begin{array}{l}\text { CONGESTION-NOS } \\
\text { EDEMA-NOS } \\
\text { SITE SPECIFIC INF LAMMATIONE }\end{array}$ \\
\hline$\stackrel{0}{\rightarrow}$ & \\
\hline 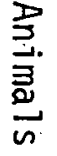 & $\begin{array}{l}\text { INFLAYMATIJN FOCAL-NOS } \\
\text { FIENOSIS-SDS }\end{array}$ \\
\hline 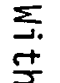 & 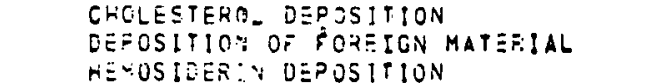 \\
\hline 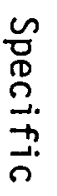 & $\begin{array}{l}\text { HYPERFLAS"A-NOS } \\
\text { HYFERLAS AA AUEVOMETOUS } \\
\text { METAPLAS IA SOUAMUUS } \\
\text { METAPLASIA OSSEOUS } \\
\text { HISTIOCYTOSIS-NOS }\end{array}$ \\
\hline$\underset{⿱ 乛}{\infty}$ & . \\
\hline$\stackrel{\vec{\rho}}{\mathrm{O}}$ & $\begin{array}{l}\text { SOUAMOUS EELL GARE:NOMA-NOS } \\
\text { AOENOMA-NES } \\
\text { AEEOCALCIVOMA-NOS }\end{array}$ \\
\hline 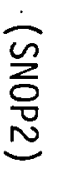 & 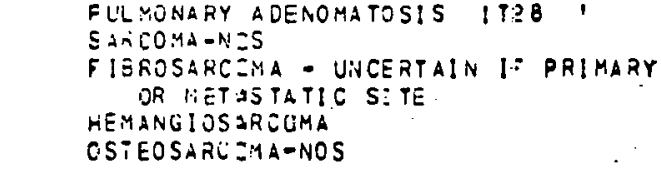 \\
\hline
\end{tabular}

SPECIESI RATS

NO, ANIMALS

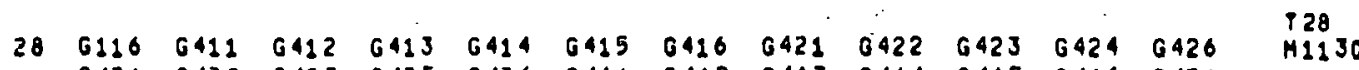
$\begin{array}{llllllllllllll}0431 & 0432 & 0433 & 0435 & 6436 & 6441 & 6442 & 6443 & 6444 & 0445 & 6446 & 6451\end{array}$ $\begin{array}{lllllll}6452 & 6453 & 6454 & 6455 & & & \\ C 24 & C 25 & 044 & 064 & 065 & 6125 & 0173\end{array}$

$30253 \quad 6173$

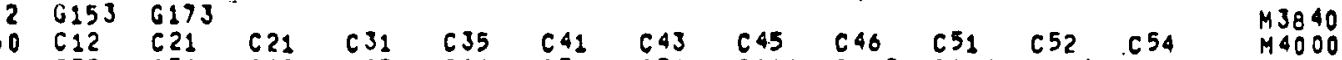
$\begin{array}{llllllllllll}C 55 & C 56 & C 62 & C 63 & C 66 & C 71 & C 76 & G 111 & 6.112 & G 114 & 0116 & G 121\end{array}$

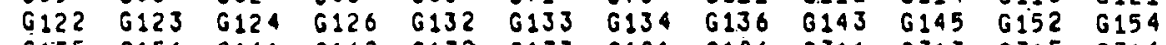

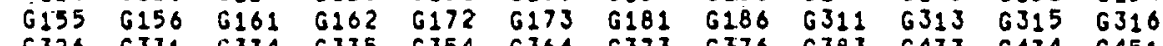
$\begin{array}{llllllllllll}6326 & 6331 & 6334 & 6335 & 6354 & 6364 & 6373 & 6376 & 6383 & 6433 & 6434 & 6451\end{array}$

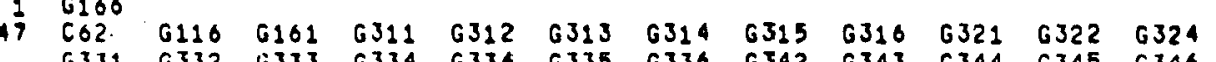

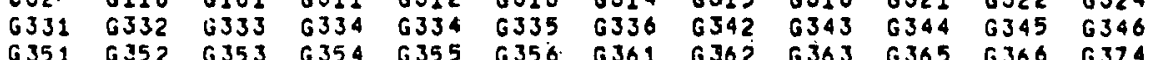

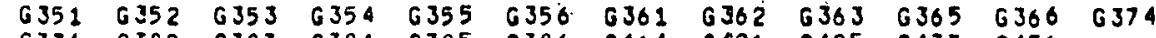

$\begin{array}{lllllllllll}6376 & 0382 & 6383 & 6384 & 0385 & 6386 & 6414 & 6421 & 6425 & 6433 & 6451\end{array}$

20410161

$\begin{array}{lllllll}6142 & 031 & 650 & 6102 & 6163 & 0164 & 0331\end{array}$

10363

120353 030 0321 03250326034503460

\begin{tabular}{llllll}
-6124 & $G 316$ & $G 321$ & 0325 & $G 326$ & 0345 \\
\hline & 0364 & $G 415$ & $G 421$ & 0433
\end{tabular}

5 C13 C5S G311 G415 6445

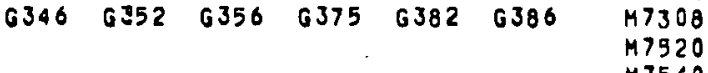

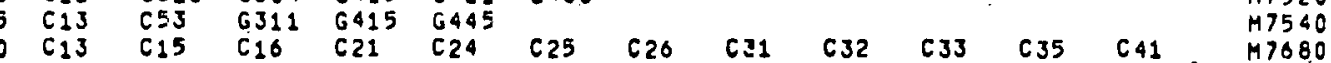
$\begin{array}{llllllllllllllll}C 43 & C 45 & C 46 & C 53 & C 54 & C 55 & C 57 & C 61 & C 62 & C 63 & C 64 & C 65 & 17680\end{array}$ $\begin{array}{llllllllllll}666 & C 72 & 074 & 6111 & 6115 & 6116 & 6121 & 6122 & 6124 & 6125 & 0126 & G 132\end{array}$ $\begin{array}{llllllllllll}0133 & G 136 & 0142 & G 144 & 0151 & 0155 & G 156 & G 161 & 6162 & 0164 & G 166 & G 171\end{array}$

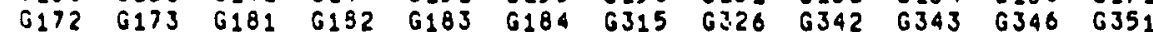

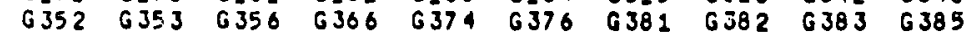

10325

$\begin{array}{llll}0133 & 6322 & 6374\end{array}$

$\begin{array}{lllll}6121 & 6325 & 6326 & 6361 & 6382\end{array}$

10113

10182

$\begin{array}{ll}1 & 6386 \\ 1 & 6362\end{array}$ 


\section{TREATMENT GROUP SUMMARIES}

The first analytical series of reports are prepared by SNOP3 and present a summary of incidence and average severity (graded i to 5) of each observation of animals in a given treatment group. Two tables are printed for each treatment group as well as a summary table comparing the treatments. The animals within a group are first ranked according to survival time, and assigned column and row coordinates for the second table. The first table, (Figure 9), lists the animal number histology number, experimental age, and coordinates. Using this table as a key, the investigator can determine, if necessary, the complete identification of a particular animal.

However, since the remainder of the reports are concerned with incidence and comparisons of treatments, individual identification is of secondary consideration; the second table (Figure 10) therefore reduces animals to a one-character code indicating the severity of any lesions. At the left of this table, each observation reported within a treatment group is printed. At the right, the severity codes are displayed, arranged from left to right in increasing order of survival time. Thus, time-related trends in the incidence and severity of a lesion within an experimental group of animals should be apparent. The center portion of this table contains the total incidence of a particular lesion and the average grade of severity.

After all diagnoses for a particular anatomical location are printed, a summary for that location is produced. This summary includes normal animals examined as well as those reported as having lesions. We have 
SHOP CODED OBSERVA-IONS BITAILED LESION INCIDENCE AND GRADES BY GROUP

EXPTI 102 (JEB). $253 E S$ INHLLATION.STUDY

SPECIESI RATS

TAMTI 3

PHE FOLLOWING TABLE IS THE XEY IO PHE TABLES HHICH SUMMARIZE OOSERVATIONS TOR OEATH THEN ASSIGNED ROW HND COLUMS INDICAPORS, TO DEPERMIVE UHICH INDIVIDUAL ANIMAL HAD A SPECIFIC

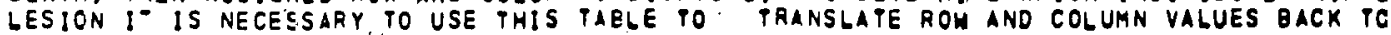

AHIMAL IOENTIFICATION NUMBERS

ANIMAL EXPT AGE COL, ROW, HISTO NO.

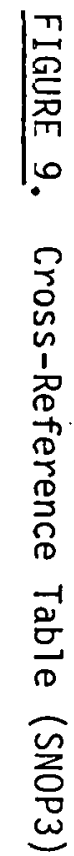

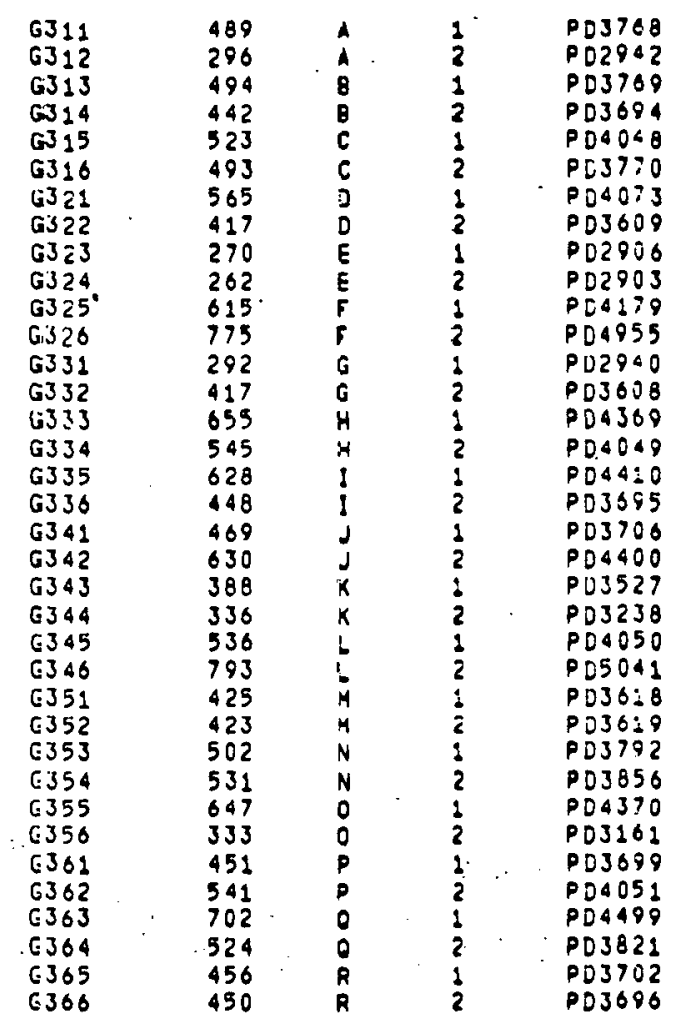


SNOP CODED OBSERYATIONS DETAILED LESSON.INCIDENCE and GRADES OY GROUP EXPTI 262 (JEB) 253ES INHALATION STUDY

SPECIESI RATS

TRHPI 3

AVE. ANIMAL COORDINATES ISEE PAGE 1

AND EJAONOSES

CONTINUEDI LUNG

HEMOSIDERIN DEPOSITION

GYPERPLASIA ADENOMATOUS

METAPLASIA SOUAMOUS

METAPLASIA OSSEOUS

HISTIOCYTOSIS-NOS

Souamous cElL CARCINOMA-NOS

ADENOMA-NOS

ADENOCABCINOMA-NOS

FEEMANGI OSARCOMA

CSTEOSARCOMA-NOS

cesteosarcoma - metastatic site

'LYMPHOMA, METASTATIC SITE

CHLOROMA. METASTATIC SITE

\section{SUMmaAY FGRS LUNO}

O NORM(N) 48 aENORM(O) O nOT EXAM(I)

$\begin{array}{ll}1 & 2 \\ 11 & 2 \\ 1 & 2 \\ 1 & 1 \\ 16 & 2 \\ 1 & \\ 2 & \\ 3 \\ 1 \\ 1 \\ 16 \\ 2 \\ 2\end{array}$

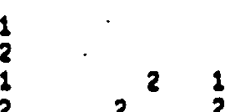

2

$2^{2} \frac{1}{2}$

:

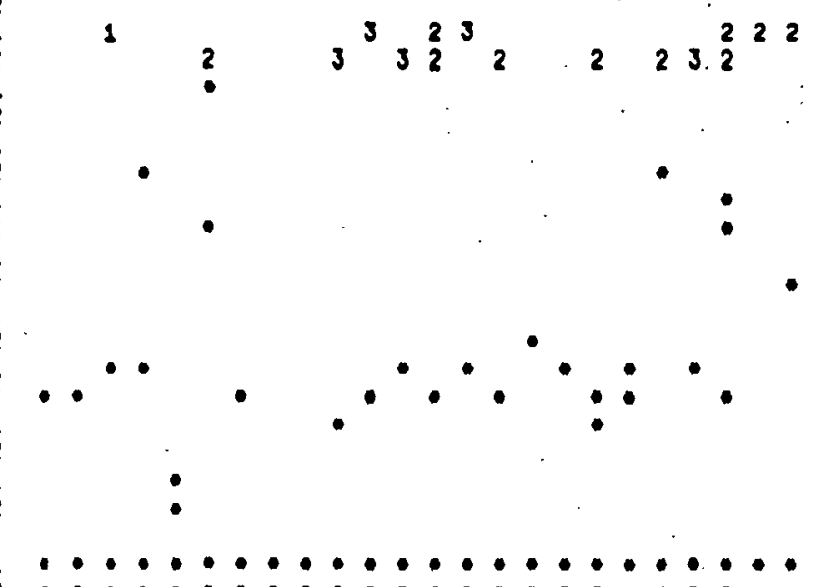

HYPERPLAS IA-NOS 
followed the convention that if a record is not entered into the system the tissue was not examined; we do not assume that a tissue was normal if no record was submitted.

The final table printed by SNOP3 (Figure 11), compares treatment groups, printing the incidence and average grade of each reported lesion type. It also contains a summary of anatomical locations, giving the number of norma 1 , abnormal, and not-examined animals in each treatment group. The right-hand column contains the totals for the entire investigation.

\section{TUMOR INCIDENCE}

Since tumors are often the lesions most important to us for evaluation of experimental results, a set of four reports, similar to the treatment group summaries but 1 imited to tumors, is printed by SNOP4, bringing together all SNOP coded tumor records (codes M8000 to M9999) to allow analysis of the types and incidence of tumors in the various treatment groups. 'These reports take advantage of the tumor classification built into the fourth (right-most) digit of the SNOP morphology codes for tumors. After consultation with our pathologists, we pooled these into three categories:

- benign - coded 0 or 1

- malignant, primary site - codes $2,3,4$, or 5

- malignant, metastatic site - codes $6,7,8$ or 9 .

The first report printed by SNOP4 is a table of tumors within these three categories. Figure 12 is an example of a malignant, prillary site table. Tumor types are printed at the left and detailed animal identifi- 
SNOP CODED OQSERVATIONS SUMMARY OF LESION INCIDENCE AND GRADES GY GROUP EXPT: 162 (JEB) $253 E S$ INHALATION STUDY

SPECIESI RA TS

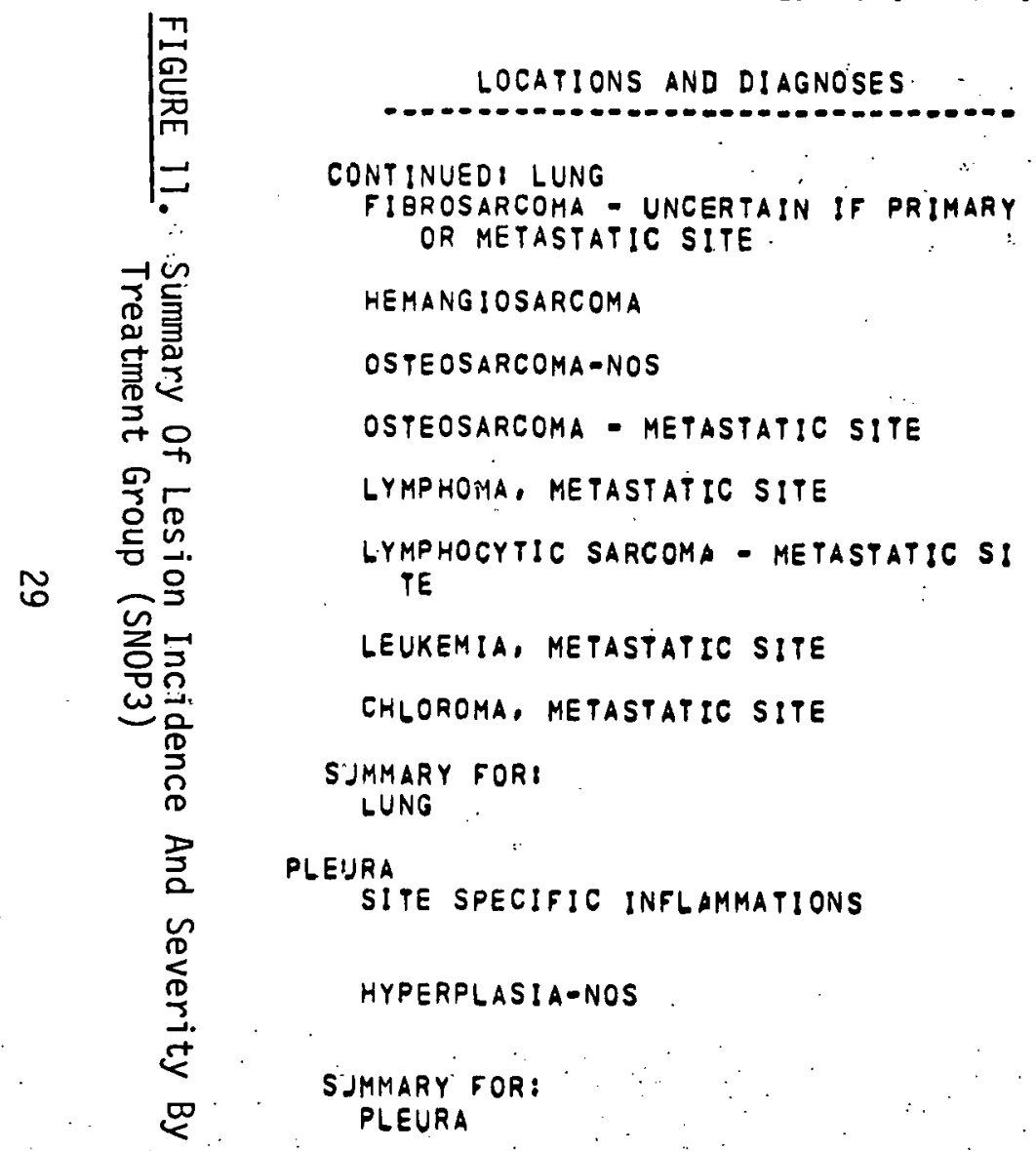

\begin{tabular}{|c|c|c|c|c|c|}
\hline $\begin{array}{l}\text { GROUP! } \\
\text { SIZEI }\end{array}$ & 36 & ${ }^{1} 45$ & 38 & $4 \%$ & $\begin{array}{l}A L L^{\circ} \\
158\end{array}$ \\
\hline $\begin{array}{l}\text { VUMBER } \\
\text { AV GRADE }\end{array}$ & & 1 & $\cdots$ & & \\
\hline IUMBER & & . & 1 & & . \\
\hline NUMBER & & & 1 . & & \\
\hline NUMBER & & & 16 & 1 & \\
\hline - NUMBER & & & 2 & & \\
\hline $\begin{array}{l}\text { IIUMBER } \\
\text { AV GRADE }\end{array}$ & & 2 & & .. & . \\
\hline NUMBER & 1 & & . & & \\
\hline NUMBER & & & 2 & & \\
\hline $\begin{array}{l}\text { I:ORMAL } \\
\text { AE NORMAL } \\
\text { NE:T EXAM }\end{array}$ & $\begin{array}{r}2 \\
34 \\
0\end{array}$ & $\begin{array}{r}3 \\
42 \\
0\end{array}$ & $\begin{array}{r}0 \\
48 \\
0\end{array}$ & $\begin{array}{r}0 \\
29 \\
0\end{array}$ & $\begin{array}{r}5 \\
153 \\
0\end{array}$ \\
\hline $\begin{array}{l}\text { NUMBER } \\
\text { AI GRADE }\end{array}$ & & $\begin{array}{l}1 \\
2\end{array}$ & & . & \\
\hline $\begin{array}{l}\text { P.UMBER } \\
\text { AI GRADE }\end{array}$ & & & $\begin{array}{l}1 \\
2\end{array}$ & & \\
\hline $\begin{array}{l}\text { NORMAL } \\
\text { ABNORMAL } \\
\text { NOT EXAM }\end{array}$ & $\begin{array}{r}0 \\
0 \\
36\end{array}$ & $\begin{array}{r}0 \\
1 \\
44\end{array}$ & $\begin{array}{r}0 \\
47\end{array}$ & $\begin{array}{r}0 \\
0 \\
29\end{array}$ & $\begin{array}{r}0 \\
2 \\
156\end{array}$ \\
\hline
\end{tabular}




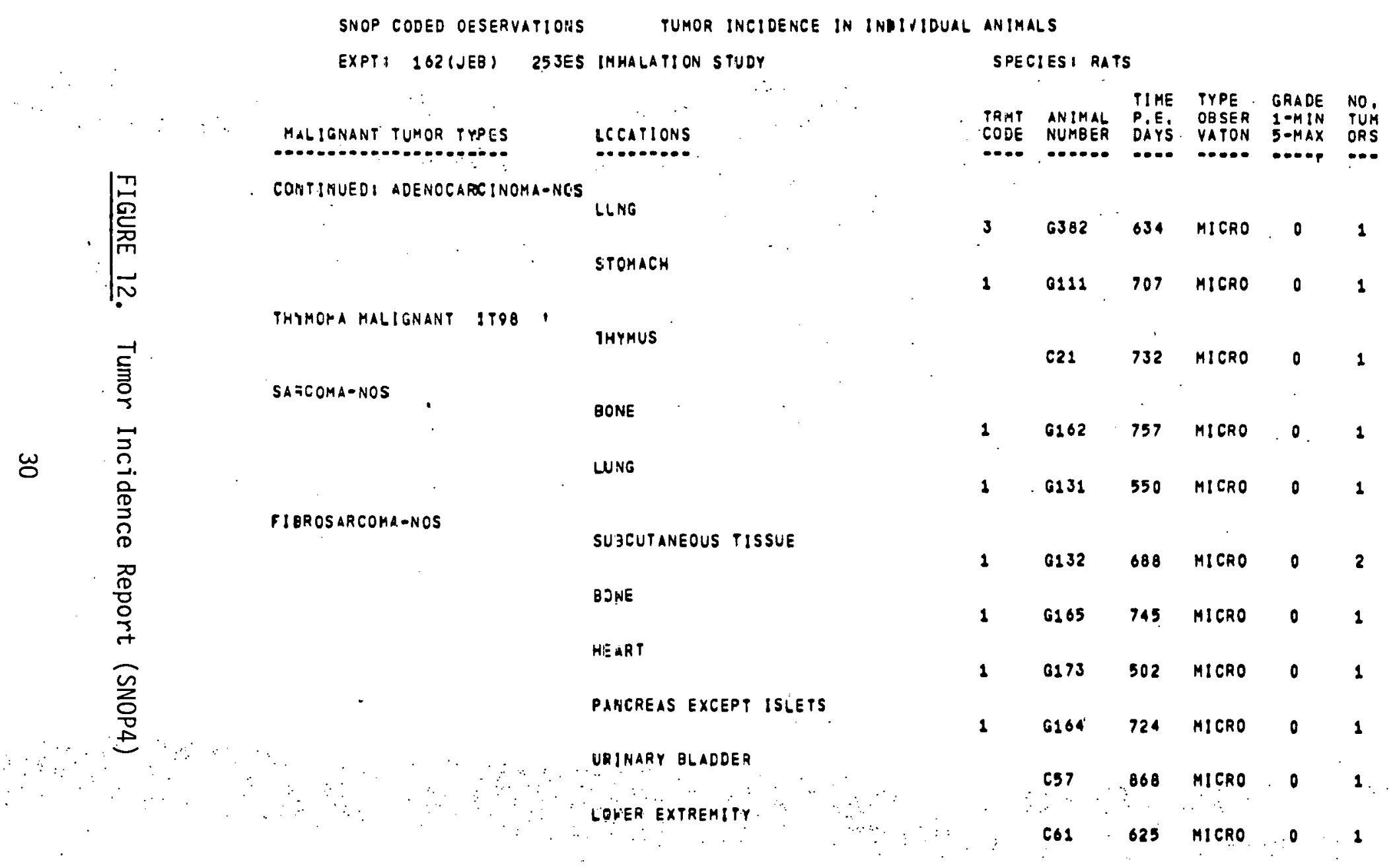


cation, including treatment code, animal number, survival time, severity and number of tumors, is printed at the right.

The second report is subdivided by treatment groups, and contains one line for each animal, giving animal identification and category of any tumor (Figure 13).

The third and fourth reports summarize tumor incidence in the various treatment groups: by category (Figure 14) and by total counts of tumors and total counts of animals having one or more tumors (Figure 15).

Animals with more than one tumor are counted in each category; however, if the conventions outlined in the section entitled "SNOP Coding Tumors" are followed, each malignant tumor will truly represent an unrelated neoplasm. 


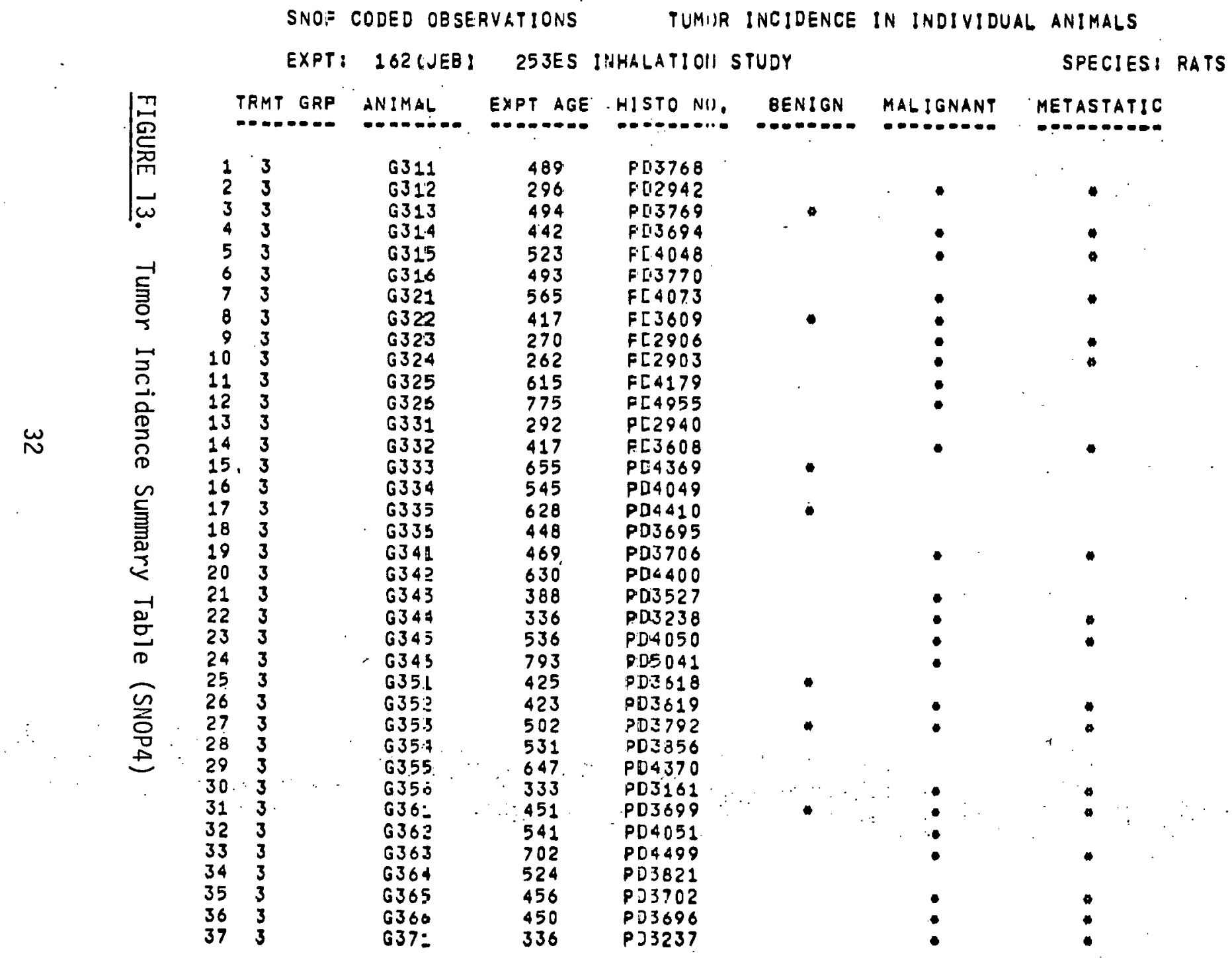




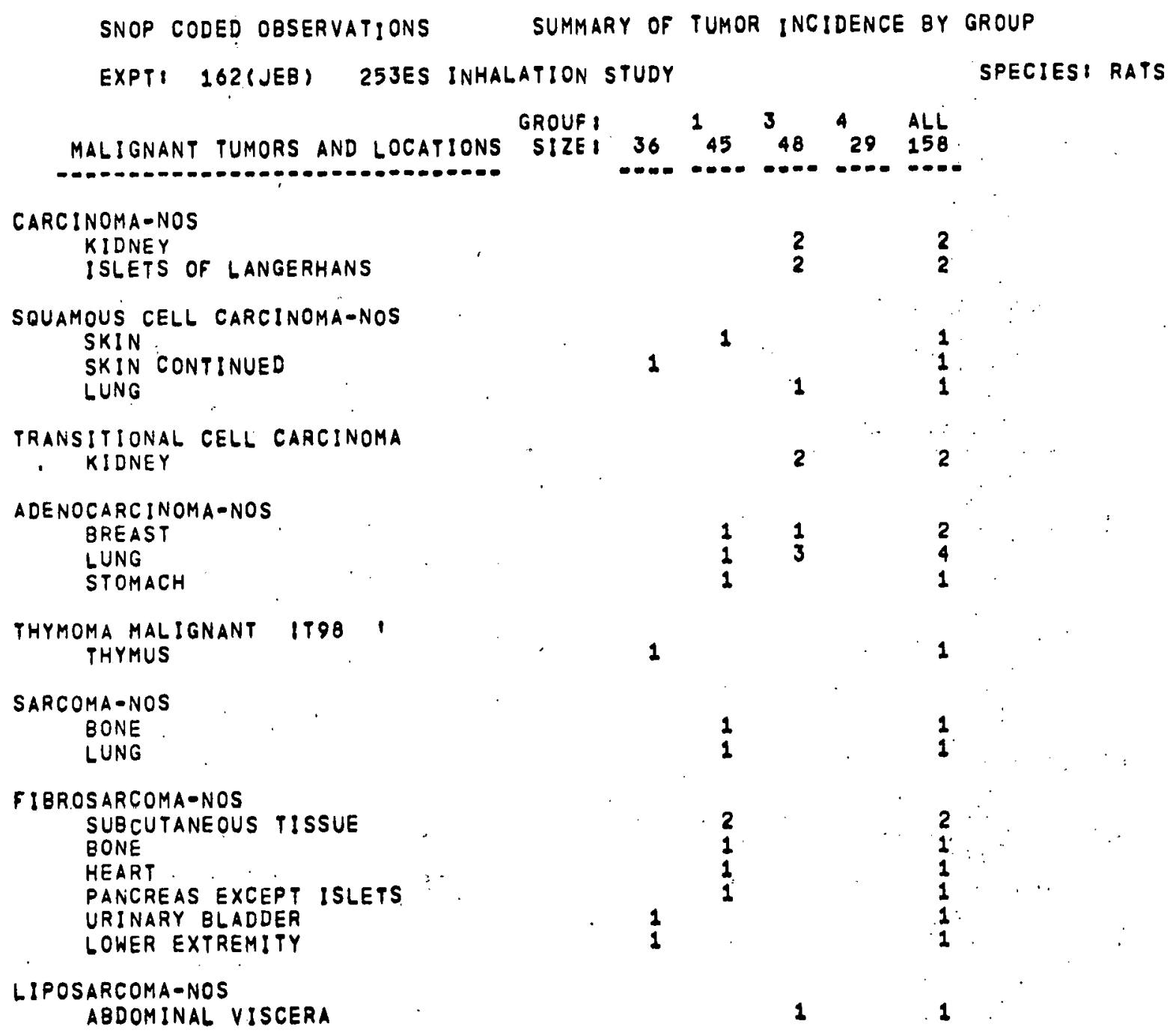

FIGURE 14.: Tumor Incidence Treatment Group Comparison (SNOP4) 


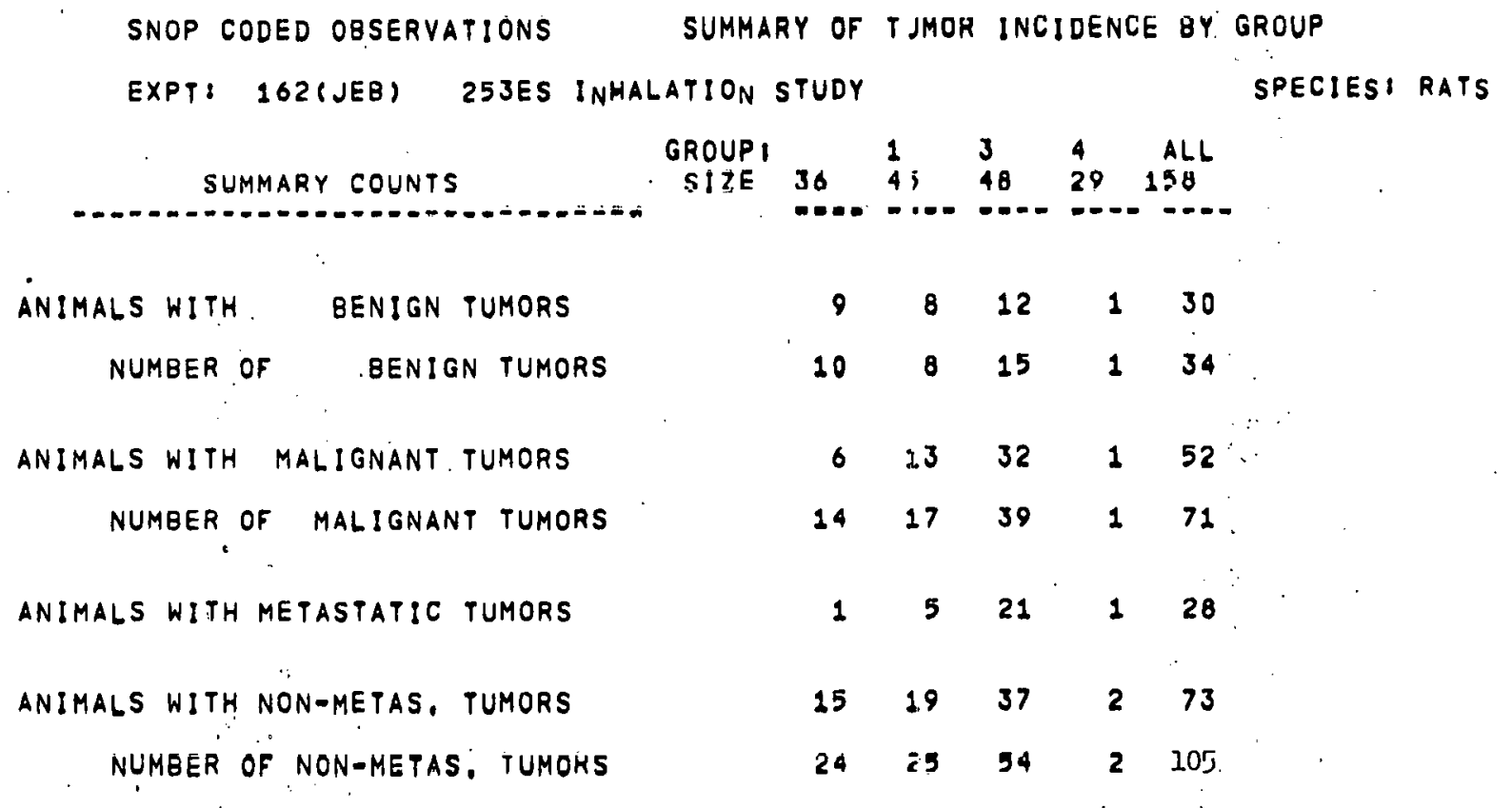

FIGURE 15. Grand Totals of Tumor Incidence (SNOP4) 


\section{COMPUTER SYSTEM}

Computer programs were written in FORTRAN for a Control Data Corporation (CDC) CYBER computer operating under SCOPE 3.4. This section describes data files, programs and production deck setups to aid compuerists in using the system. A7though standard FORTRAN was used as much as possible, the following areas represent machine-dependent CDC-CYBER characteristics of the system:

- 60-bit word length

- CDC compass functions to compare and manipulate characters

- CDC record manager routines to access the SNOP dictionary and data files

- CDC SORTMRG routines to manipulate data files.

We have attempted to incorporate a sufficient number of comment cards within each program to make the program listings self-evident. These listings (on microfiche) appear as Appendix A; punched card copies of the SNOP programs are available on request. The following section consists of documentation describing how to set up and run each program, as well as general run diagrams and flowcharts.

The overall flowchart for the system is present in Figure 16. SNOPI creates condensed data files from the HI input data for use by SNOP2, SNOP3 and SNOP4. A11 corrections and additions to the data base must be performed by submitting $\mathrm{HI}$ cards to SNOPI with subsequent merging into existing data files. It is anticipated that the SNOPI program possibly coupled with SNOP2, will be run several times to get the data base complete 


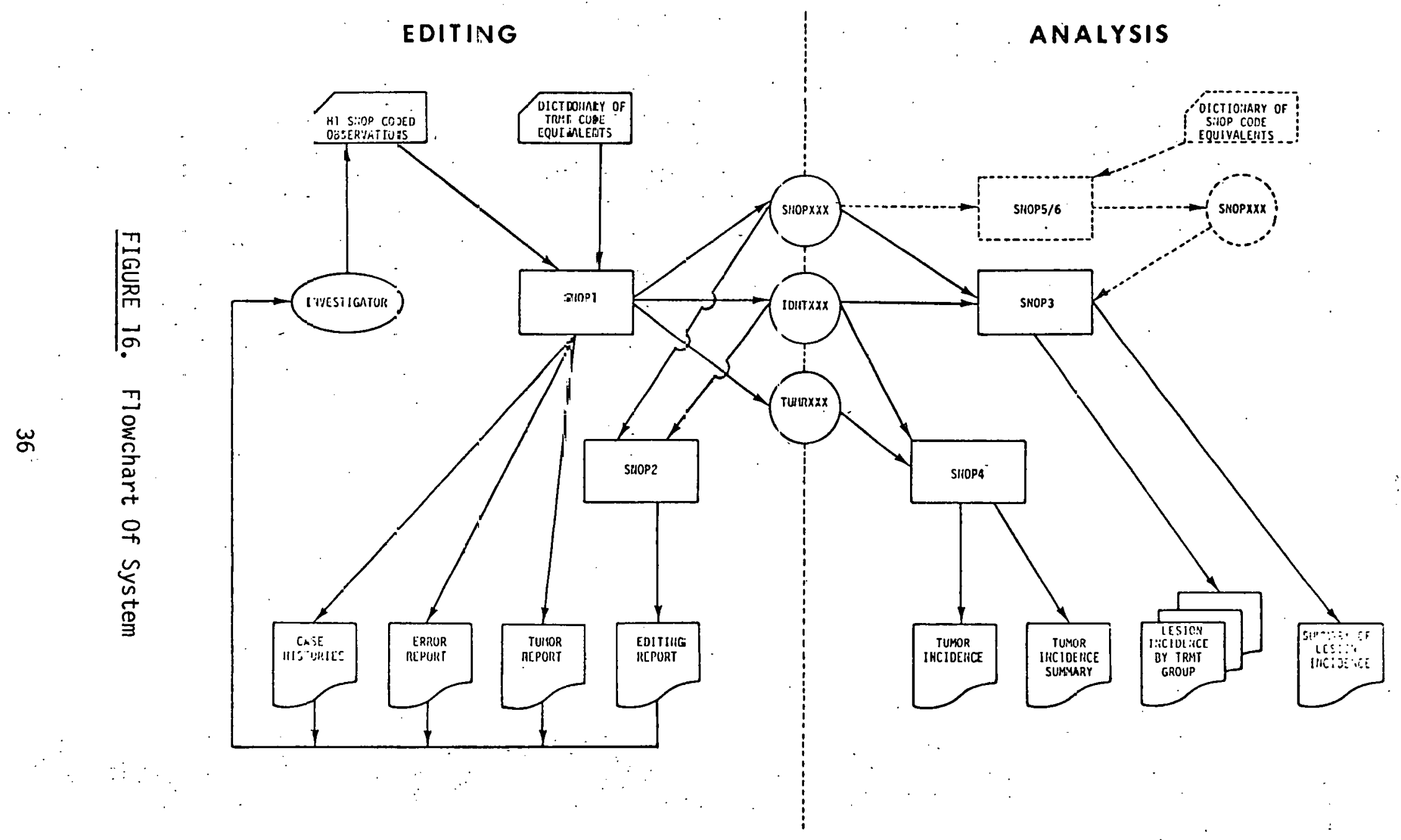


and acceptable to users. After examining original runs from SNOP3 and SNOP4, users may want to condense lesion descriptions further for the final report. These temporary changes can be performed by SNOP5/SNOP6 which create modified files to be rerun on SNOP3 and SNOP4.

\section{FILE STRUCTURES}

The data files, either cards or mass storage, are segregated by experimental groups for efficiency in analysis. The files are identified by a unique three-character suffix associated with standard file names. In the description, "XXX" is used to represent these identifiers, although different characters (such as investigators' initials) would be used for éach data set established. Data files are maintained on disk files during active analysis, then transferred to tape files for storage.

The SNOP dictionary containing English equivalents is maintained on a disk utilizing a Direct Address file organization. Each record contains the 5-character code (E, F, M or T prefix and 4-digit code) and a 1- to 75-character English translation. The file was created from and is updated from punched cards, using the Systematized Nomenclature of Pathology dictionary as a guide. Only the preferred terms were entered with synonyms, and site-specific terms are not included. Some deviations from the standard codes are being used to accommodate our particular needs; these are entered in a master SNOP handbook maintained by the Biometrics Center after the changes are approved by the users.

Figure 17 presents the parameters and characteristics of the file. Program CHANGE is used to update the file, while access is accomplished by calls to the SNOPS subroutine. In both cases the FORTRAN callable 
Record Format (cards, mass storage or KSNOP array)

$\begin{array}{lcc}\text { Code Prefix ( } T, M, E, F) & A i & 1 \\ \left.\text { SNOP Code (Numeric with } X^{\prime} s \text { and } Y^{\prime} s\right) & A 4 & 2-5 \\ \text { English Equivalent } & 7 A 10, A 5 & 6-80\end{array}$

Parameters (used by CDC Record Manager Routines)

$\begin{array}{lll}\text { File Organization } & \text { FO } & \text { DA } \\ \text { Logical File Hame } & \text { LFN } & \text { SNOP } \\ \text { Record Type } & \text { RT } & \text { W } \\ \text { Minimum Record Length } & \text { MNR } & 5 \\ \text { Maximum Record Length } & \text { MRL } & 80 \\ \text { Record Key Word } & \text { RKW } & 0 \\ \text { Record Key Position } & \text { RKP } & 0 \\ \text { Key Length } & \text { KL } & 5 \\ \text { Home Blocks } & \text { HMB } & 1000 \\ \text { Maximum Block Length (Characters) } & \text { MBL } & 630 \\ \text { Records Per Block (average) } & \text { RB } & 15\end{array}$

Creation - punched cards submitted to program CREATE.

Updating - additions, replacements or deletions performed by program CHANGE along with a SCOPE card to EXTEND the file.

Rarkun (usina Tane Recervation Svstem)

ATTACH (SNDP, SNOPCODE, ID=BNW331

TAPESET (SINORCODES, ID=BNW331, $\forall=S N O P C O D E S, N C=2$, RET $=999$, PRUGE)

TAPE (SNOPTAP, SNOPCODES, ID=BIWW331, $W=S N O P C O D E S$ )

COPY (SNOP, SNOPTAP)

SAVETAP ( SNOPTAP

Access (utilizes subroutine SNOPS)

COMMON /BLKSNOP/

CALL OPNSINOP<smiles>[13CH3]</smiles>

KEYSNOP $=$ KCODE

CALL GETSNOP

:

CALL CLSSNOP
SNOPFIT( 35$)$, KSNOP(8), LSNOP, KEYSNOP, KEYNEXT

Record Manager Array Working Array Length in characters Code to look up Next code to look up Opens file at beginning

Set code to look up Looks up English equivalent and fills KSNOP array according to record format Closes file at end.

FIGURE 17. SNOP Dictionary Characteristics 
routines to RECORD MANAGER are used to get, put, replace and delete records from the file, which is copied to magnetic tape for backup.

The form $\mathrm{HI}$ (Figure 2 and description on page 9 ) is filled out by users and submitted to the Biometrics Center for processing. It is keypunched to produce one card for each lesion or coded observation (Figure 18). The forms are then accumulated, by experiment, until the investigator requests a report. The cards are subsequently inputted to SNOPI, after which they are filed for backup. The program SNOPI creates SNOPXXX, TUMRXXX and IDNTXXX files (Figures 18 and 19) which are the basis for the other programs. Errors are generally corrected in the backup deck and a duplicate card reentered to the program SNOPI to generate correct records for the IDNTXXX, SNOPXXX, and TUMRXXX files. These additional records are merged into the existing files with SORTMRG.

The IDNTXXX file consists of one record per animal to provide animal treatment, age and histology number for reference in each of the reports (Figure 18). The information is currently obtained entirely from the $H T$ forms, although eventually the treatment and age data could be obtained from a computer managed inventory of experimental animals.

All coded observations are stored in the SNOPXXX file in a condensed format (Figure 19). The "remarks", "date observed" and "observer" (Form H1) are not stored -- users must reference the SNOPI report for them. Although the TUMRXXX file is in the same format as SNOPXXX, it is limited to neoplastic lesions coded M8000 to M9999. 


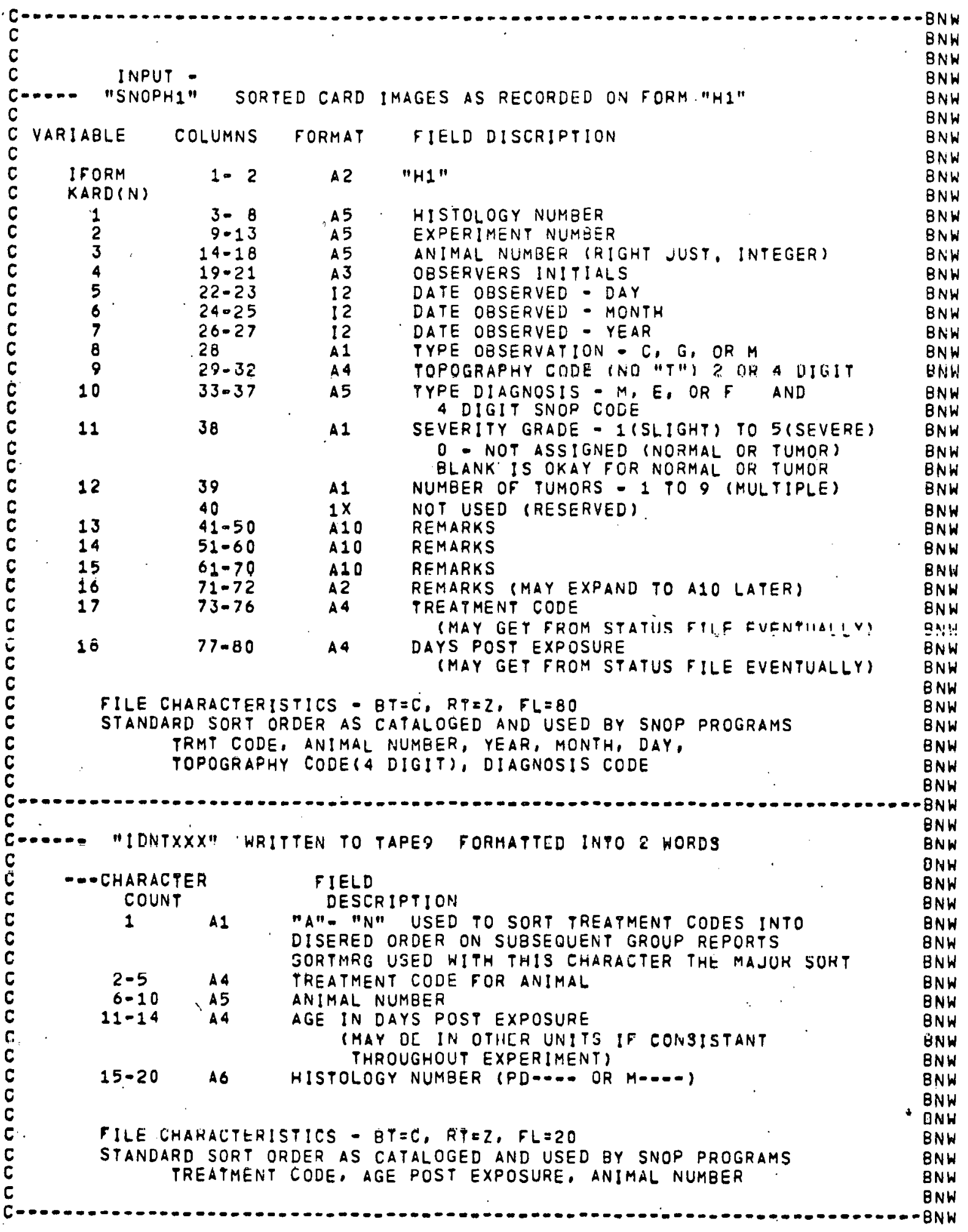

FIGURE 18. HI Input and IDNTXXX File Characteristics 


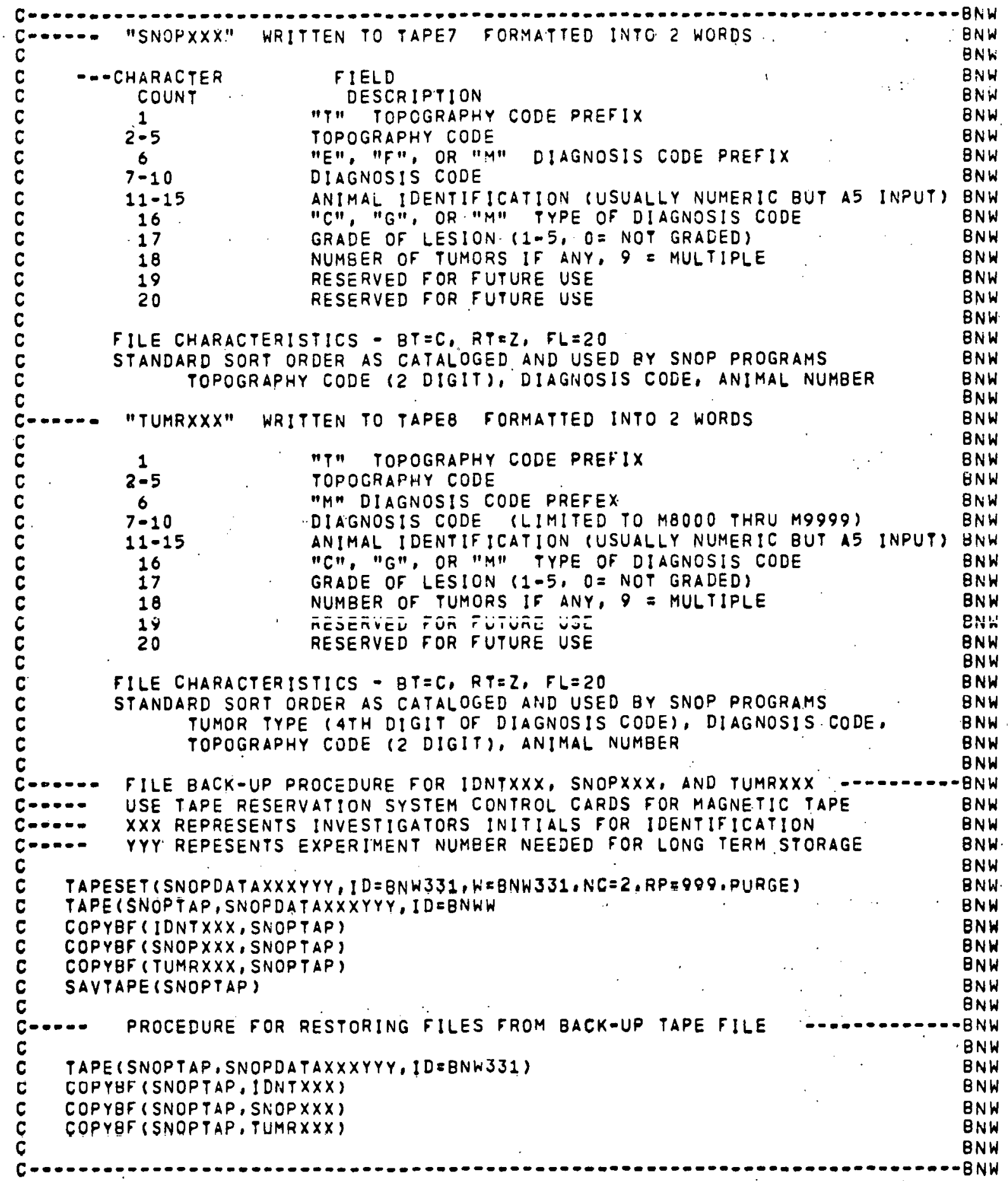

FIGURE 19. SNOPXXX And TUMRXXX File Characteristics 
PARAMETER CARD

A parameter card defining the type of report format and the experiment characteristics is a necessary input to all SNOP1, SNOP2, SNOP3 and SNOP4. The format of this card is shown in Figure 20.

PARAMETER CARD
IREOUIRED FOR SNOPI, SNOPZ, SNOPJ, AND SNOP4)

FIGURE 20. Parameter Card Format 
SNOP1

SNOPI is the foundation program used to read new data and to create appropriate files for input to other report generating programs. A typical sequence of processing a set of data with SNOP1 would be:

- Submit keypunched $H J$ forms to SNOPI, as outlined by Figure 21 ,

- Have pathologist check errors and verify completeness of data,

- Rerun SNOPI and run SNOP2 for additional error checking and editing,

- Correct any remaining errors,

- Rerun SNOPI for final case history reports, microfiche copy and creation of data files including tape backup,

- If any other changes are needed or new data added, submit just those cards to SNOPI and merge resulting records into existing files.

At this point the complete and correct data files are ready to be submitted to SNOP2, SNOP3 or SNOP4 for report generation.

The flowchart and program abstract are presented in Figures 22 and 23 . The characteristics of the $\mathrm{HI}$ form are discussed on page 8; output reports are described starting on page 15. A parameter card is necessary as outlined in Figure 20 which can generally be used for all the programs. SNOP1 also may read a dictionary of treatment code equivalents to modify the treatment codes entered on the $H I$ forms. This allows setting several codes equal to a common code such as changing $C$, CON or CONT all to CONT which would insure all the control animals would be grouped together in subsequent 


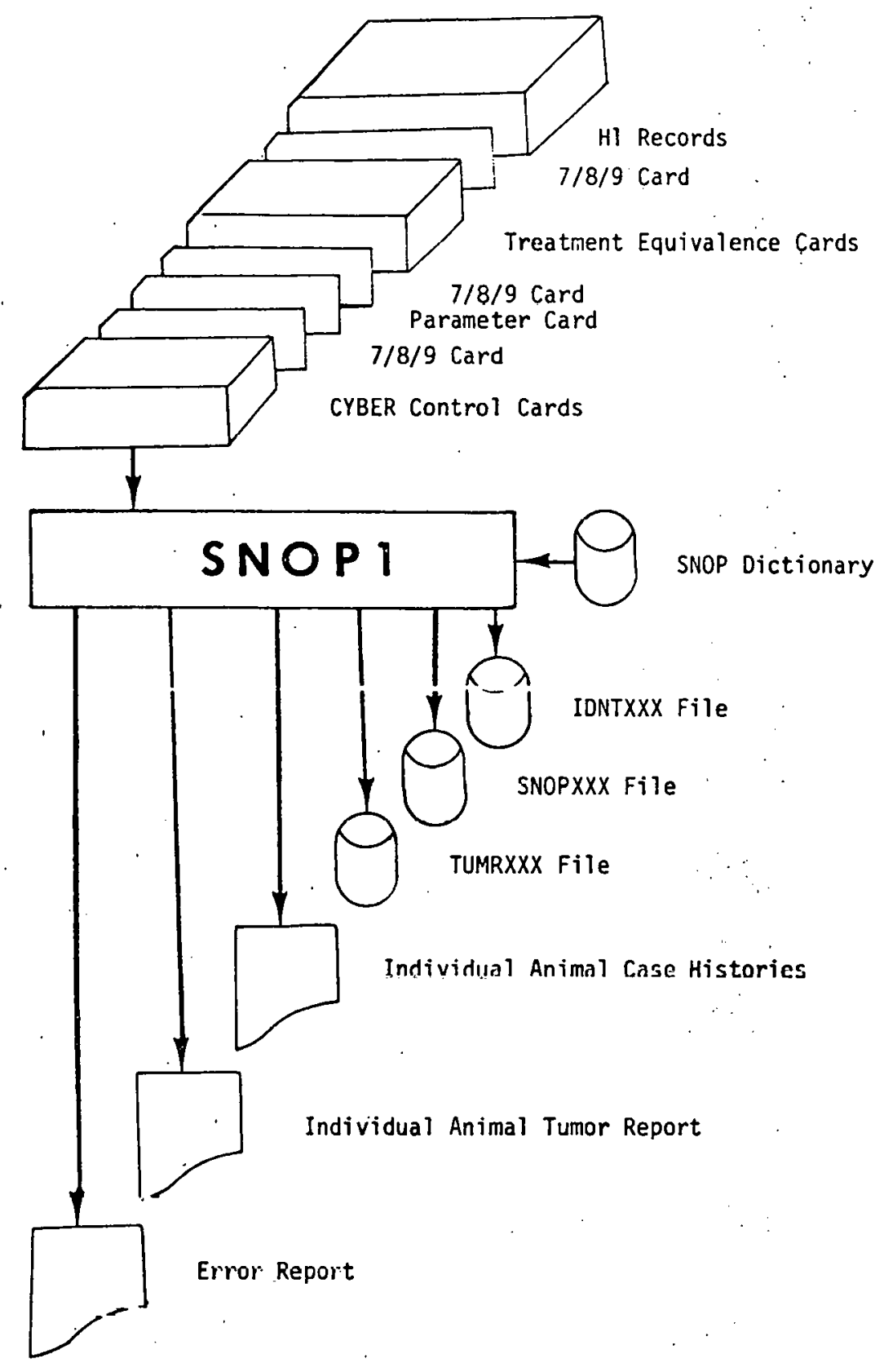

FIGURE 21. SNOP1 Run Diagram 


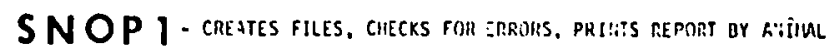

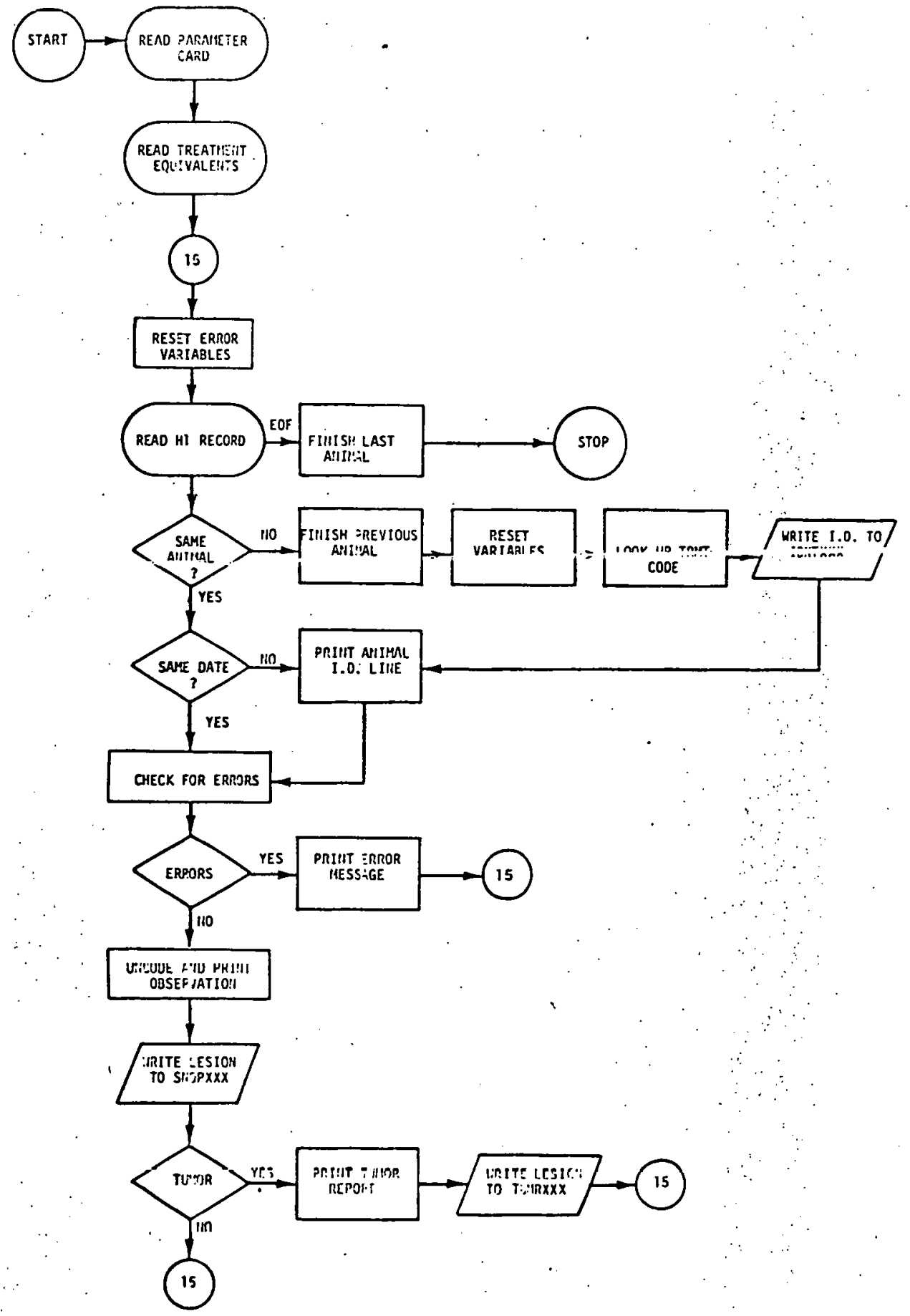

FIGURE 22. SNOPI Flowchart 


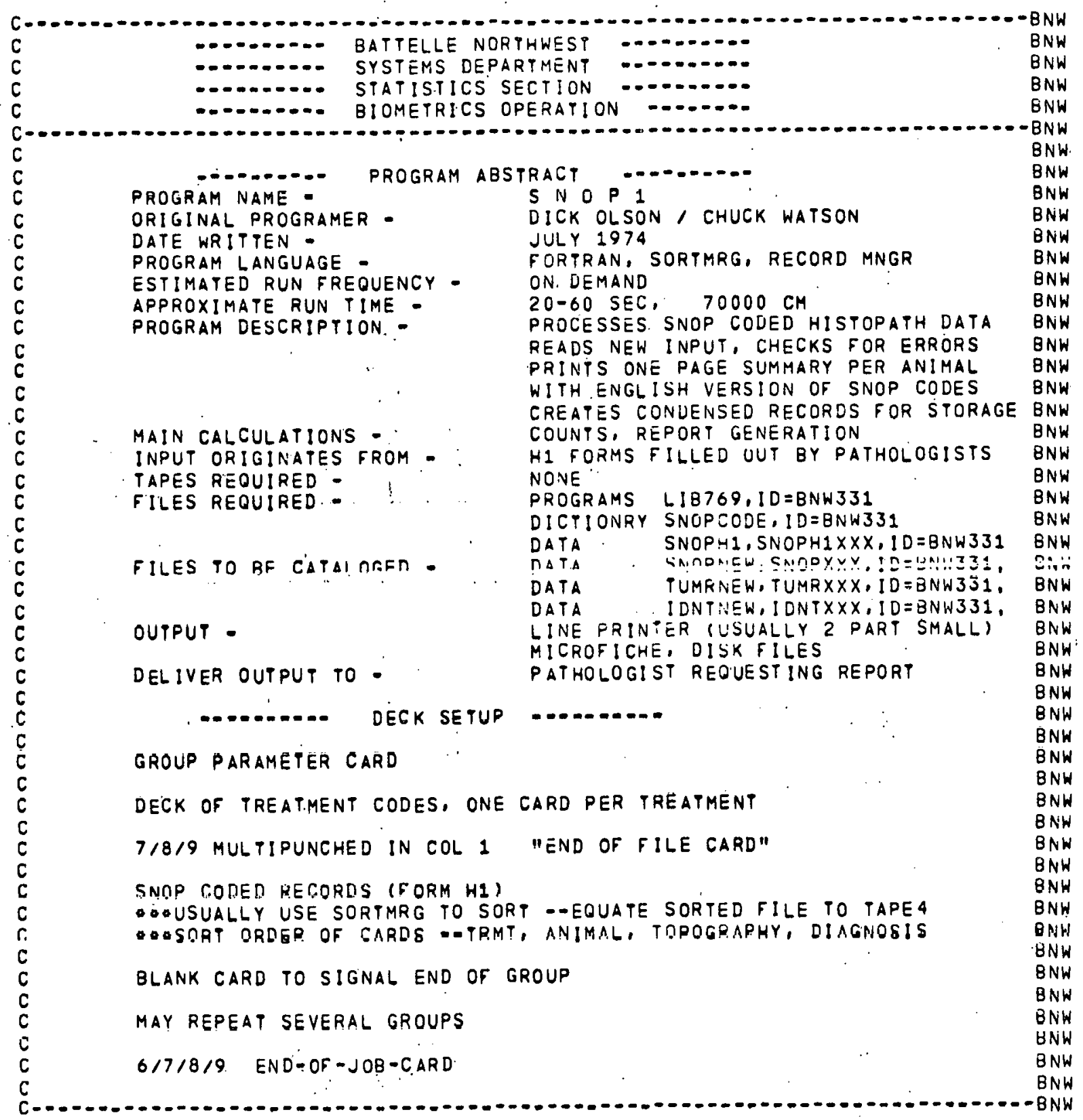

FIGURE 23. SNOPI Program Abstract 
reports. The first character on each dictionary card is used to determine the output order of treatment groups in summary programs. If no dictionary is used, the treatment codes wi1l be taken from the $\mathrm{HI}$ records and arranged alphabetically in the various reports. The format for these cards (one per treatment) is:

Col 1 Character determining order of treatments in reports

Col 2-5 Desired 4 character treatment code to appear on reports

Col 6-10 Various 4 character codes equivalent to desired code and 11-15 converted to the code in columns 2-5. A total of 15

16-20 variations of the desired code can be entered $(15(A 4,1 X))$.<smiles>[3H][Pb](O)=[18O]</smiles>

Considerable file handling is performed in a SNOPI run as the input data is sorted and output files are sorted or sort-merged before cataloging as permanent files. The standard sort order for the various files are:

- SNOPHI (HI format)

Treatment, animal number, observation date, topography code, diagnosis code

- IDNTXXX (Animal identification)

Treatment, experimental age, animal number

- SNOPXXX (A11 lesions)

Topography code ( 2 digit), diagnosis code, animal numbèr

- TUMRXXX (Tumor lesions)

Tumor type, diagnosis code, topography code (2 digit), animal number

The program has extensive error checking and message writing to detect problems in the data. We have used logical variables to indicate errors and to determine which messages to print. Records with errors will not be 
written to the condensed files and the data analyst must resolve these errors with the pathologist before the data base can be completed. The rekeypunched, corrected cards are resubmitted to SNOP1 and the resulting records merged into the original files rather than reprocessing the entire set of data each time another error is found.

\section{SNOP2}

The SNOP2 program generates a list of all lesions in an experimental group to be used for editing purposes (see page 21). Figure 24 shows the deck set up and associated input/output files while the flowchart and abstract are presented in Figure 25 and 26 . The program accumulates animal numbers in an array for each lesion (Figure 25). When a different lesion type is read from the SNOPXXX file, the preceding lesion is decoded and printed along with the array of accumulated animal numbers. Morphologically normal (M0001.) observations are skipped in the printout to condense the output.

The cross-reference tables in SNOP2, SNOP.3 and SNOP4 are created by a call to SNOPID which reads IDNTXXX and saves the animal numbers in., drrays (Appendix A). Subroutine SNUPID will cause abnormal program termination if more than 15 treatment groups or more than 1000 animals are processed. This routine creates indices arranged by animal number that point to the individuals nriginal input sequence arrarlyed by trcatment and age pos.t exposure. Subroutine SNOPSRT performs an internal "shell" sort to arrange the animal numbers while subsequent calls to subroutine BINSRCH 


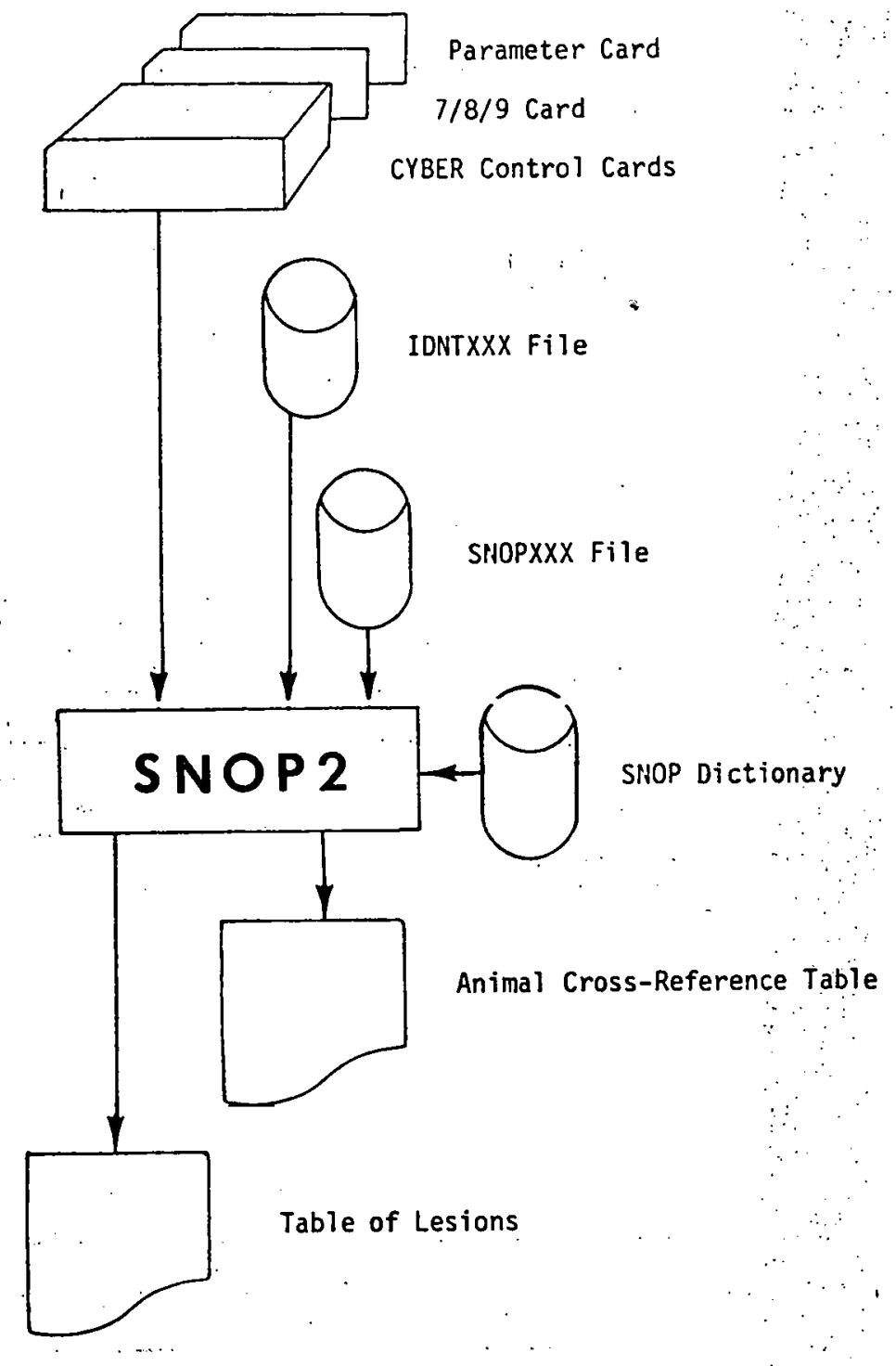

FIGURE 24. SNOP2 Run Diagram 
SNO P2 - L:STS ALL LESLIUIS III GRUUP

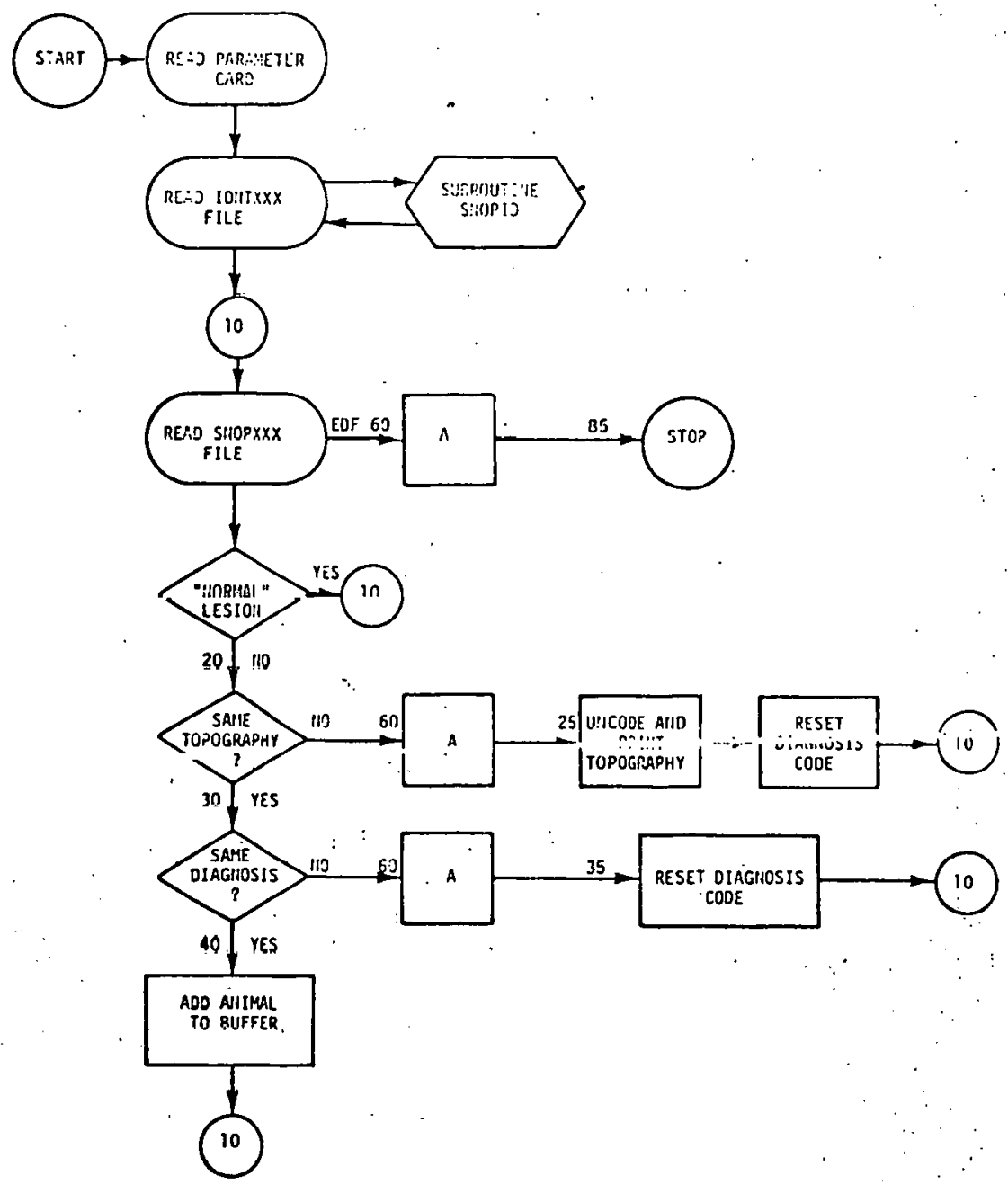

A. Internal Routine

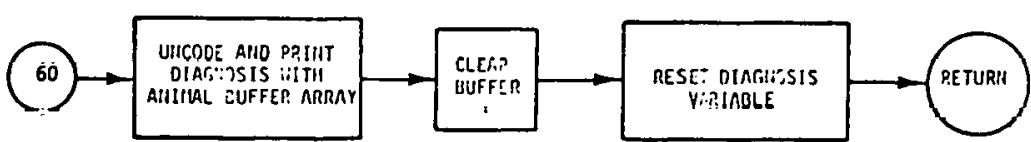

FIGURE 25. SNOP2 Flowchart 


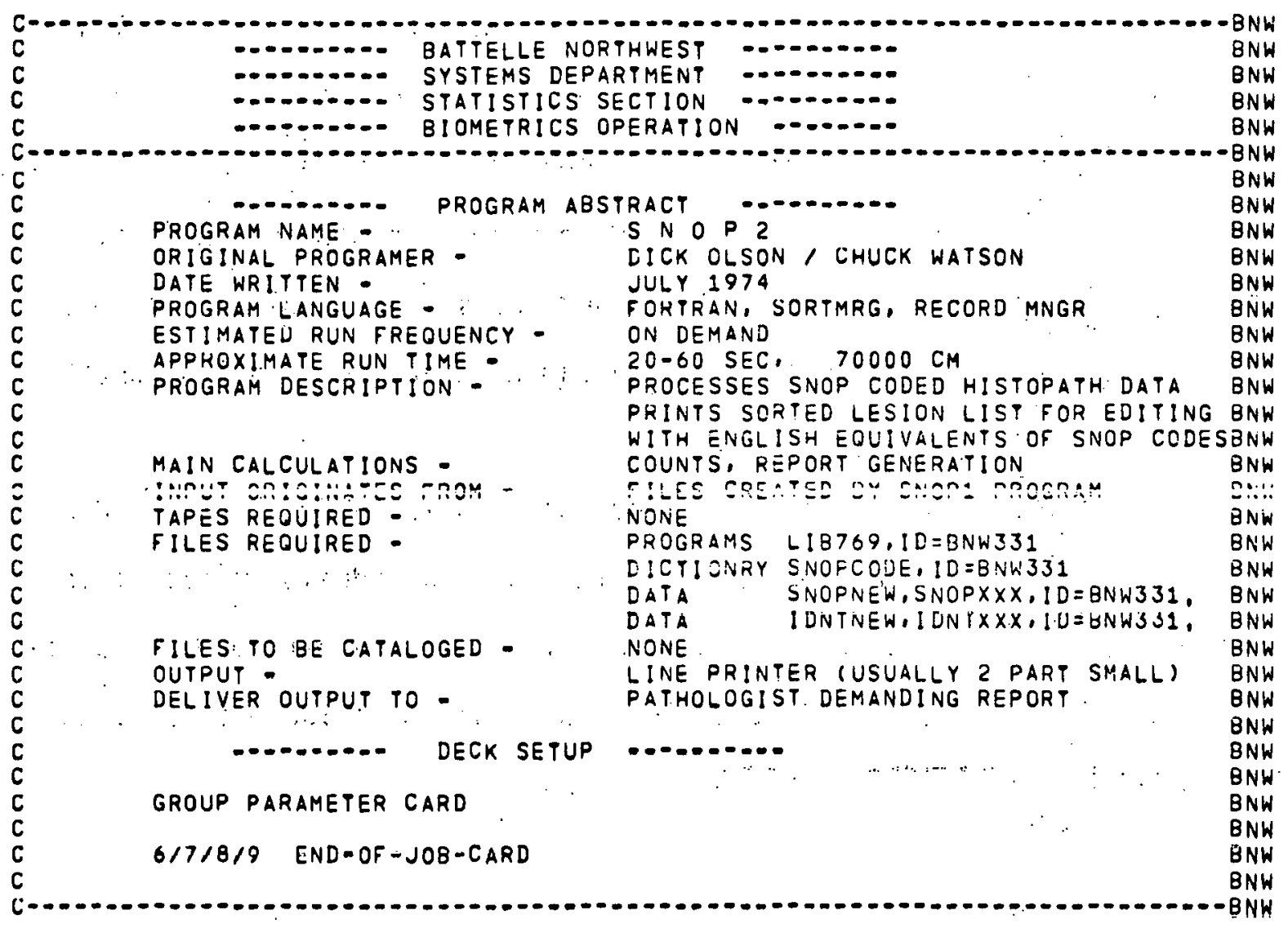

FIGURE 26. SNOP2 Program Abstract 
looks up animal numbers in the index arrays (Appendix A). This routine utilizes a binary searching technique.

SNOP3

Tables for comparative analysis of the incidence and severity of lesions are produced by SNOP3. This program performs detailed tabulations to determine which individuals' are completely "normal" or those with one or more lesions (see page 25). The deck set up and associated input/ output files are shown in Figure 27; the flowchart and program abstract in Figures 28 and 29.

SNOP3 writes separate output files for each treatment group plus a summary report to an additional file. SCOPE file handling cards are used to copy these separate reports to a common print file which can be printed or disposed to microfiche. The maximum number of output files (i.e. treatment groups) is 14 , with a 15th used for summary tables. Increasing this will require changing the program card and re-compiling SNOP3 along with revising the SCOPE deck.

This program also uses the subroutines SNOPID, SNOPSRT, and BINSRCH as described under.SNOP2 to arrange data from individuals according to increasing ages post-exposure. All observations, whether normal, pathogenic or neoplastic, are included in this report to allow proper calculation of the incidence of various lestons. 


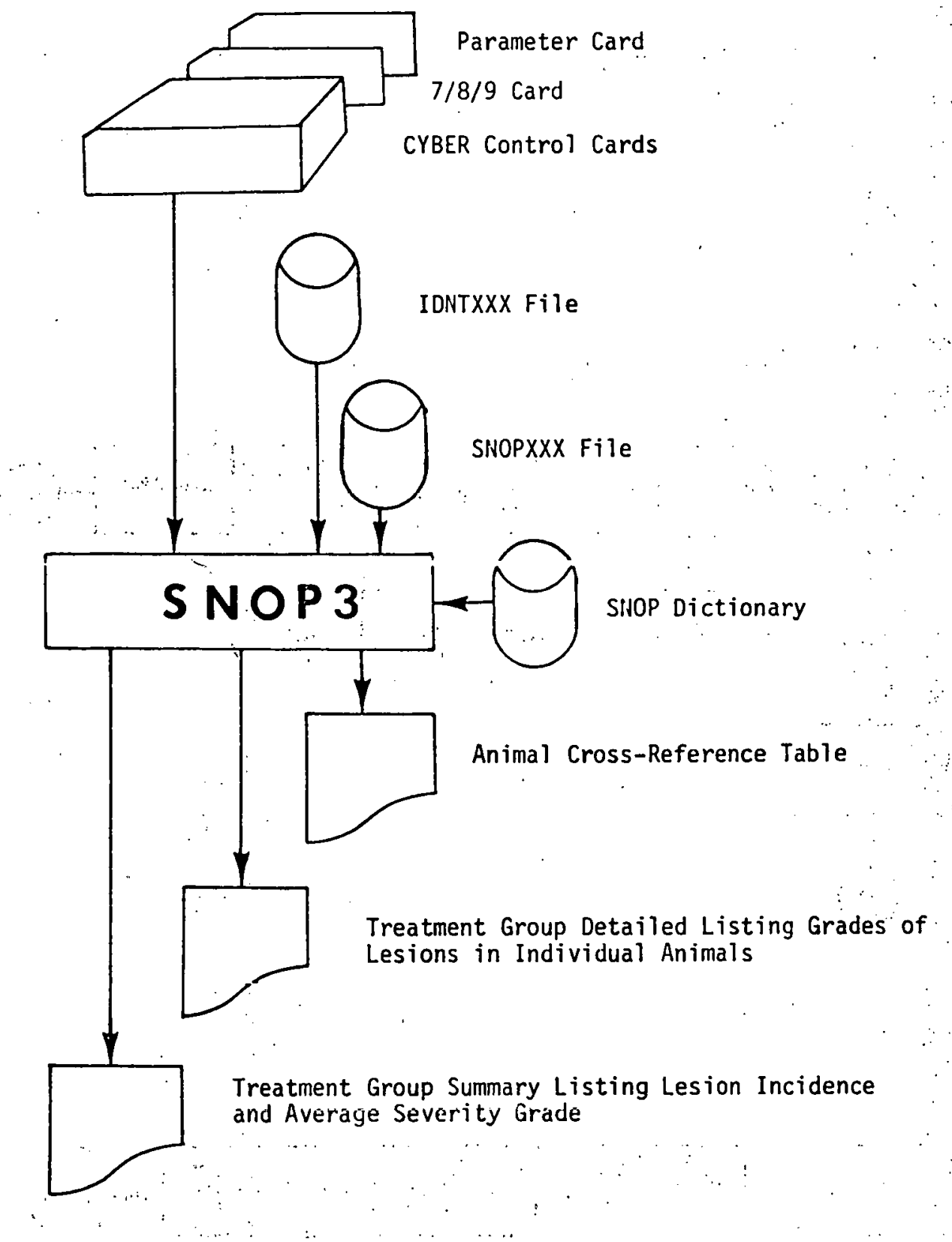

FIGURE 27. SNOP3 Run Diagram 


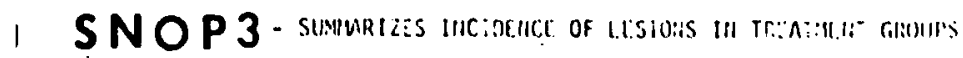

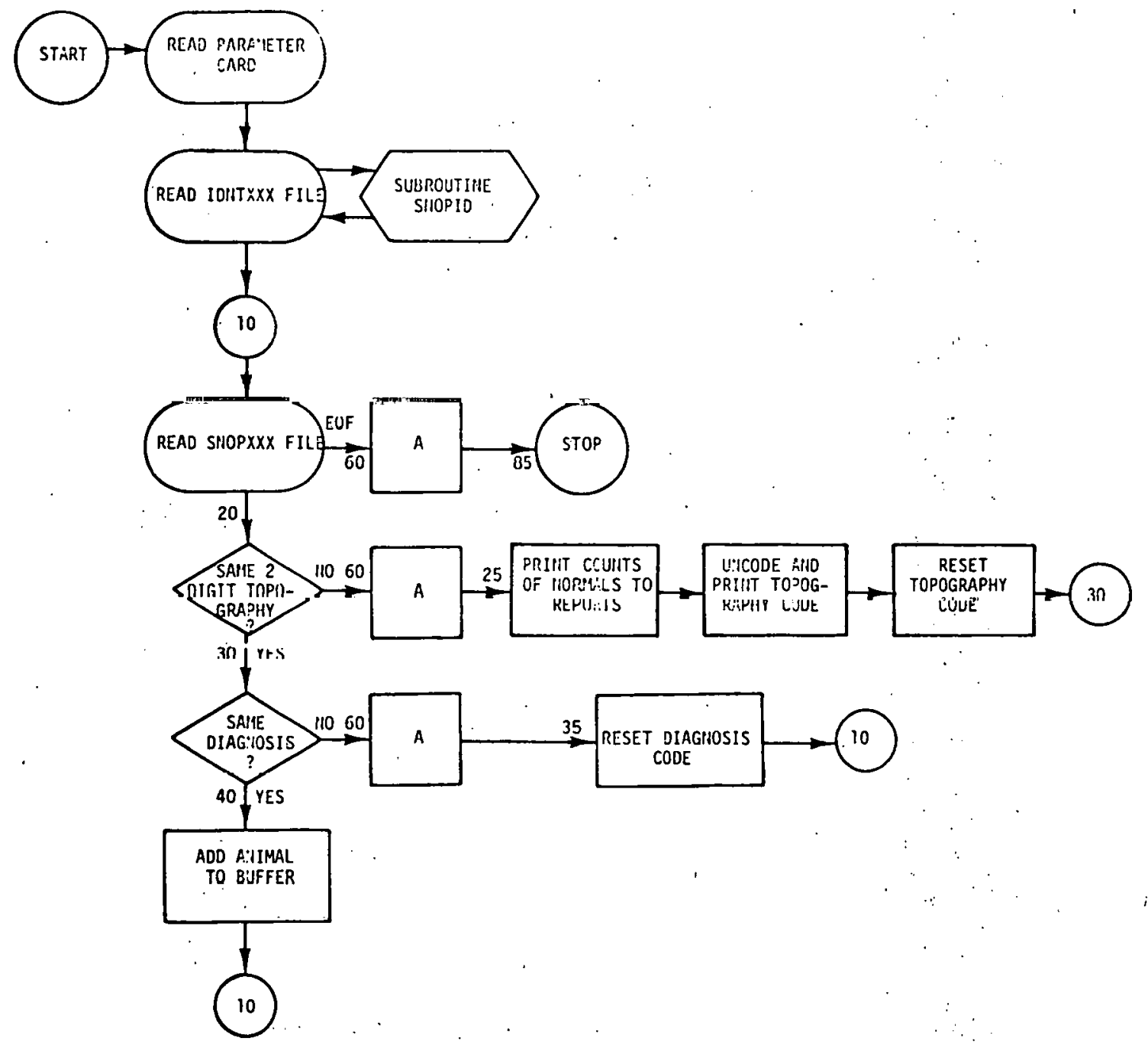

A. Internal Poutine

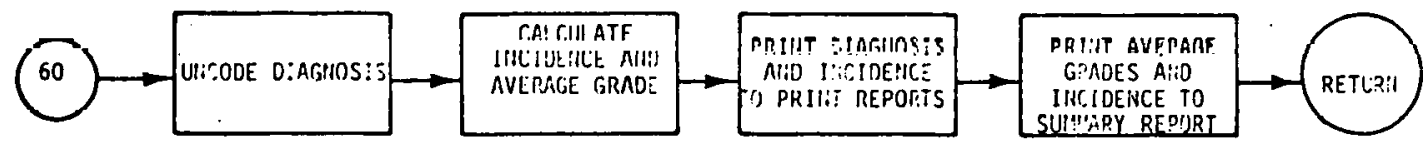

FIGURE 28. SNOP3 Flowchart 


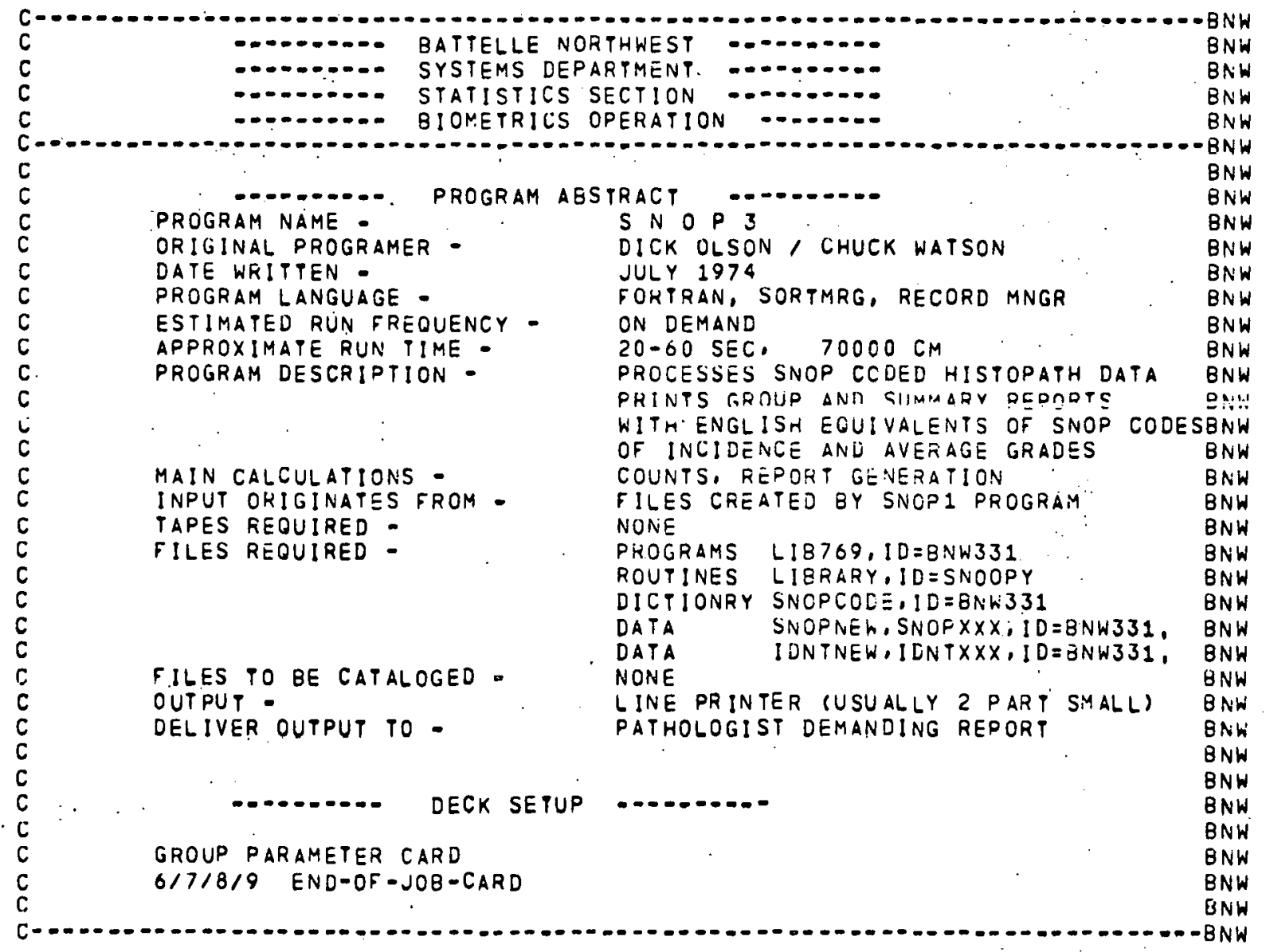

FIGURE 29. SNOP3 Program Abstract 
Tables for comparing the incidence of neoplastic changes are printed by SNOP4. The usefulness of this program depends on the pathologist following the conventions described on page 11 . The output records are described on page 27 and include tables of the number of tumors and number of animals with tumors. The program makes these tables assuming that if there is more than one tumor record per animal the tumors are truly independent. This convention is reasonable with primary màlignant sites but the counts for benign or metaplastic neoplasms must be interpreted knowing that several or many related benign or metastatic lesions may be observed within various organs of the same animal. Figure 30 presents the deck set up input/output files while the flowchart and program abstract are given in Figures 31 and 32 . 


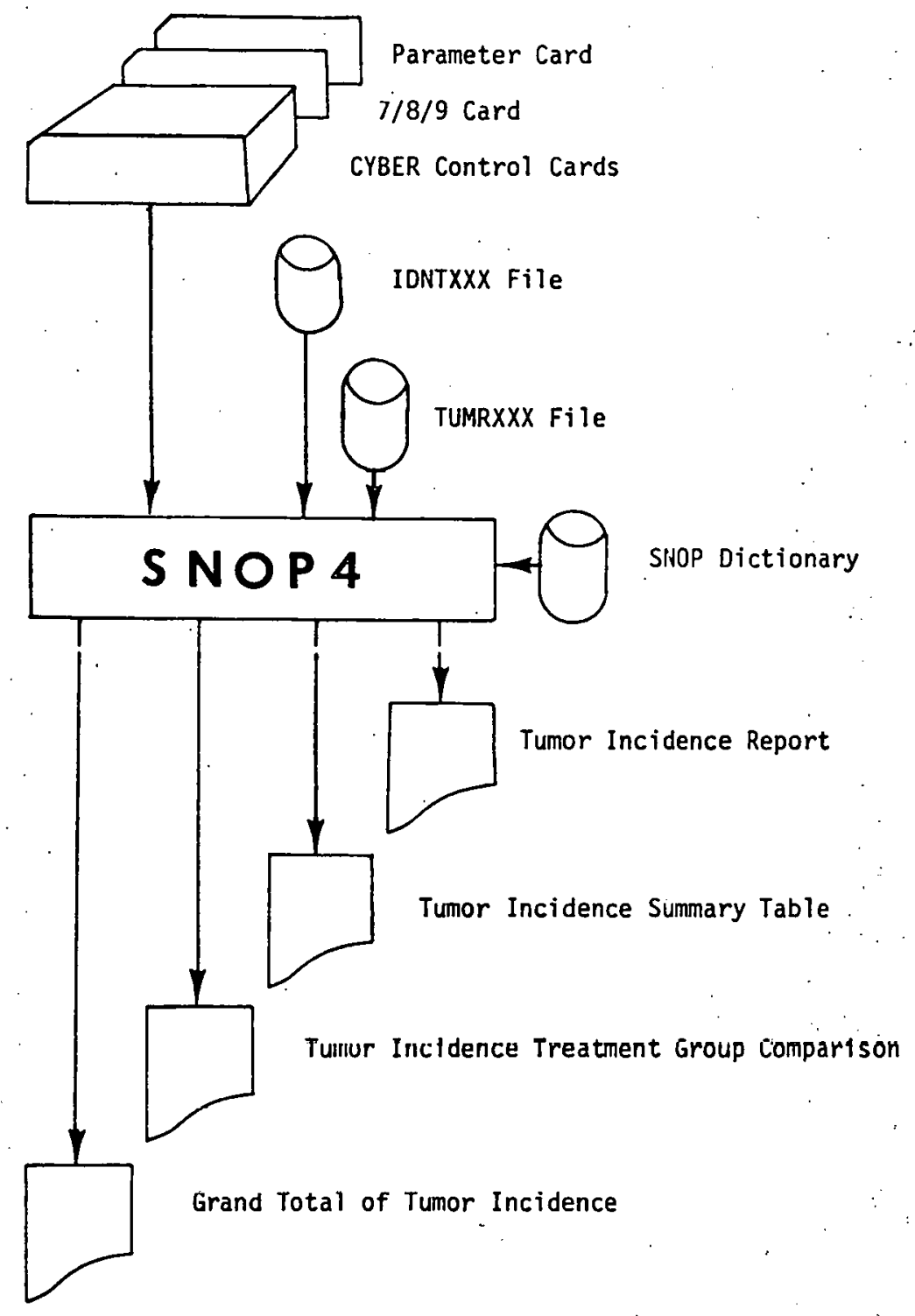

FIGURE 30. SNOP4 Run Diagram 
SNOP. 4 - surmarizes inciochec Of turt.jRs III groups

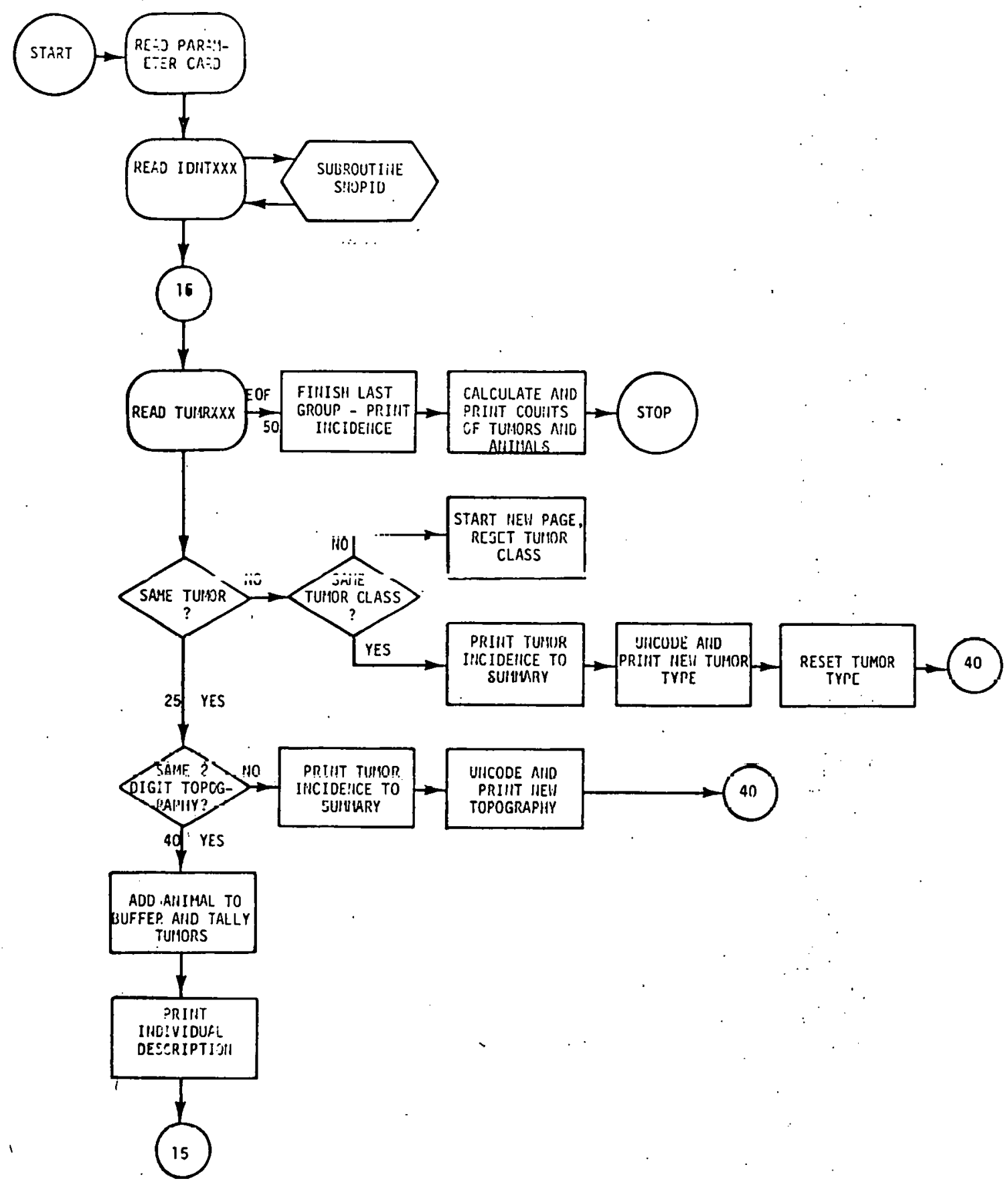

FIGURE 31. SNOP4 Flowchart 


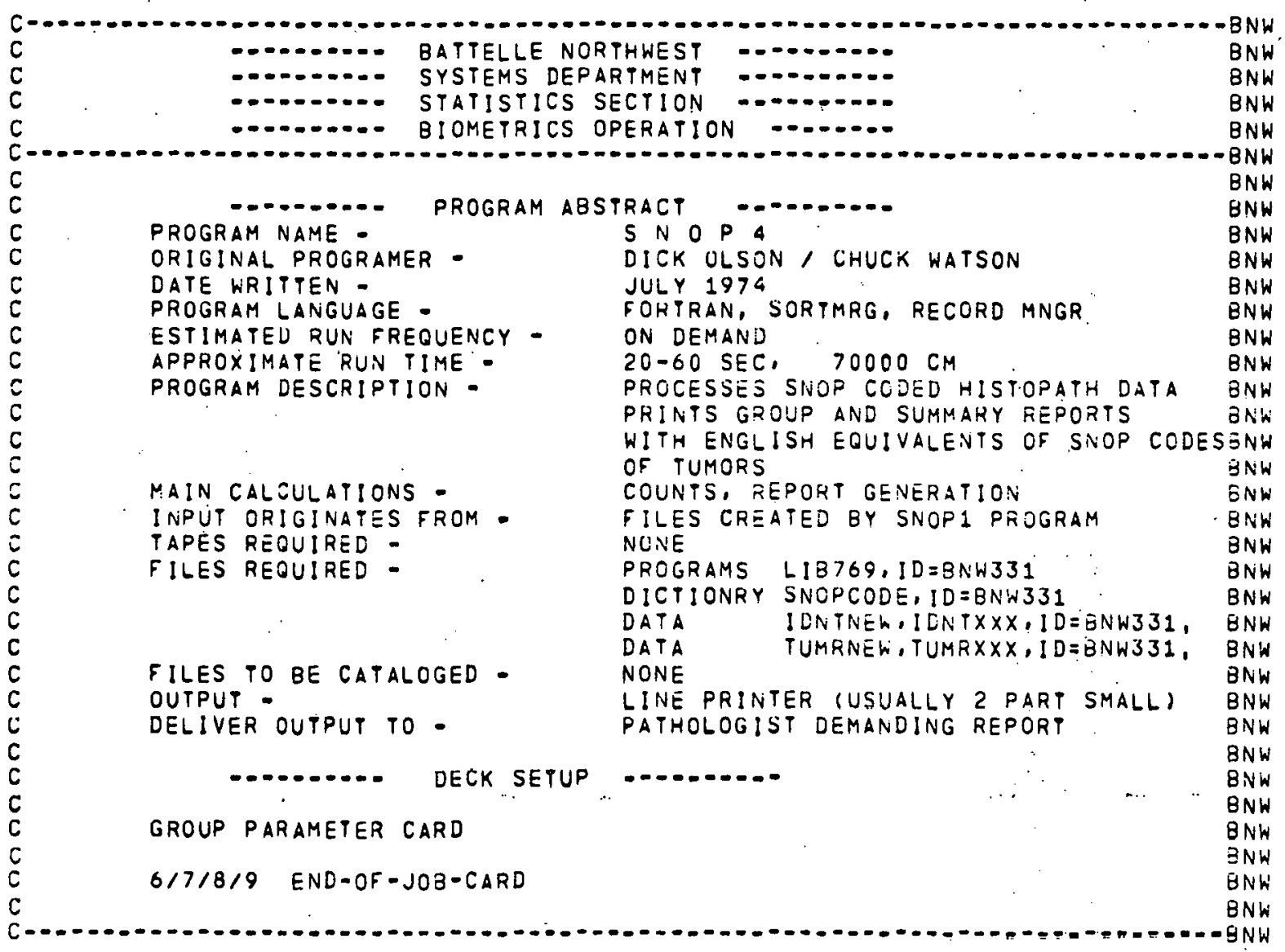

FIGURE 32. SNOP4 Program Abstract 
SNOP5/SNOP6

These two programs are run concurrently to perform temporary editing of SNOPXXX or TUMRXXX files (Figure 33). SNOP5 modifies topography codes according to a user define set of code equivalents (see page 12). The resulting file is sorted by SORTMRG and utilized by SNOP6 to change diagnosis codes (morphology, etiology or function). This file is sorted and cataloged as SNAPXXX or TAMRXXX and submitted to SNOP2, SNOP3 or SNOP4 to generate the appropriate reports. The only reason to have two programs is to allow the external sorting between the two parts. The flowchart is present in Figures 34 and 35 and the program abstracts in Figures 36 and 37.

SNOP5 reads the dictionary of code equivalents and creates an array of words with the first five characters representing the existing code and the rightmost five characters being the code that will be used as the replacement. After the entire dictionary is created, it is sorted into the same order as the input file (SNOPXXX or TUMRXXX) for processing. If a two digit topography code is entered, then a match on two digits is adequate to cause a replacement. Also if "DROP" is entered for the replacement code, the matching lesions will be dropped from the new file.

Diagnosis changes are read by SNOP5 but are written to mass storage to be used by SNOP6. An optional field is included to indicate a topography qualifier, i.e. one may want to modify inflammatory changes to a common lesion code only if they occurred in the lung.

As more experience is gained with the SNOP codes, we may be able to develop a standard dictionary defining equivalent codes. However, we 


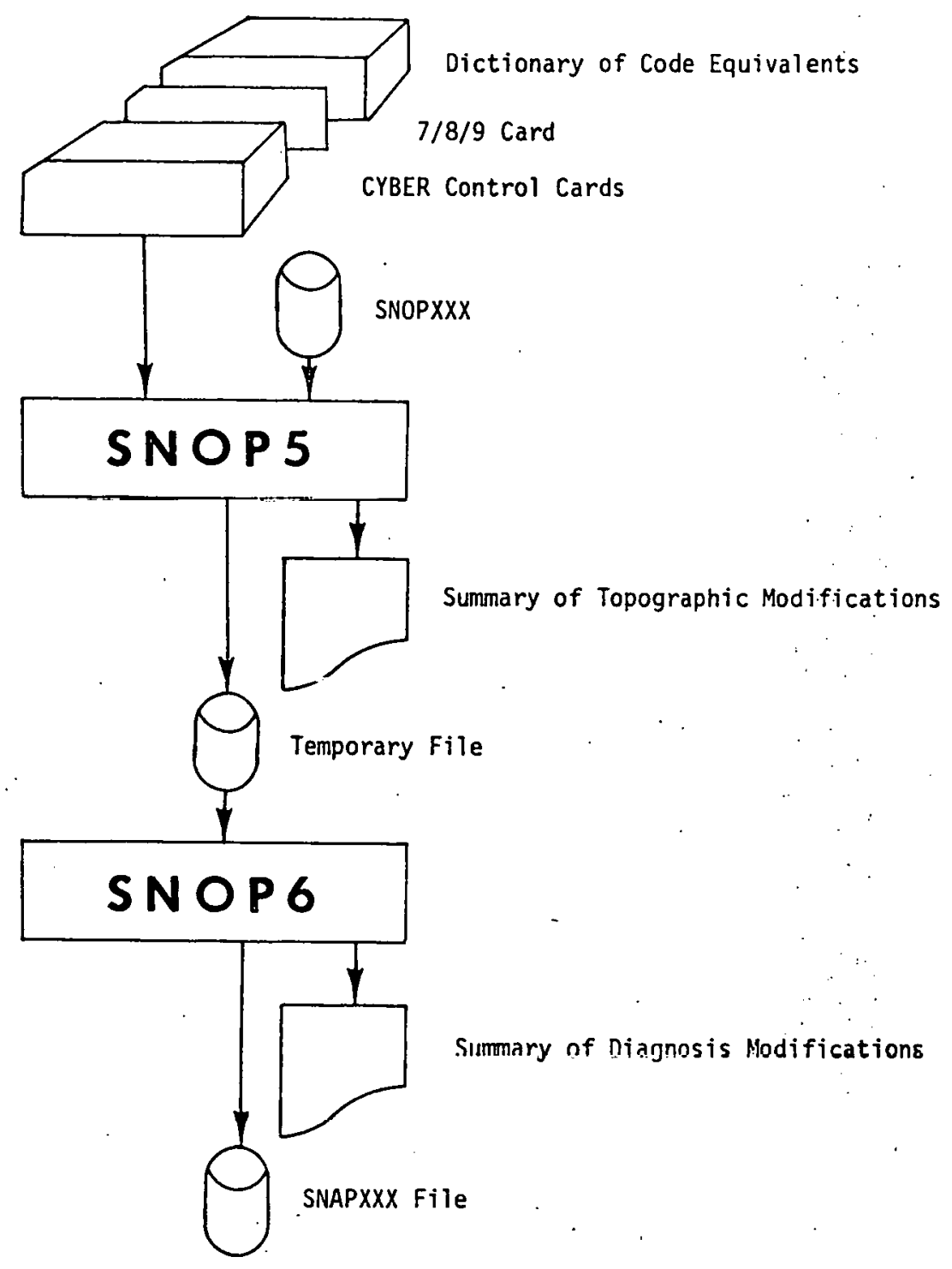

FIGURE 33. SNOP5/SNOP6 Run Diagram 


\section{SNOP 5}

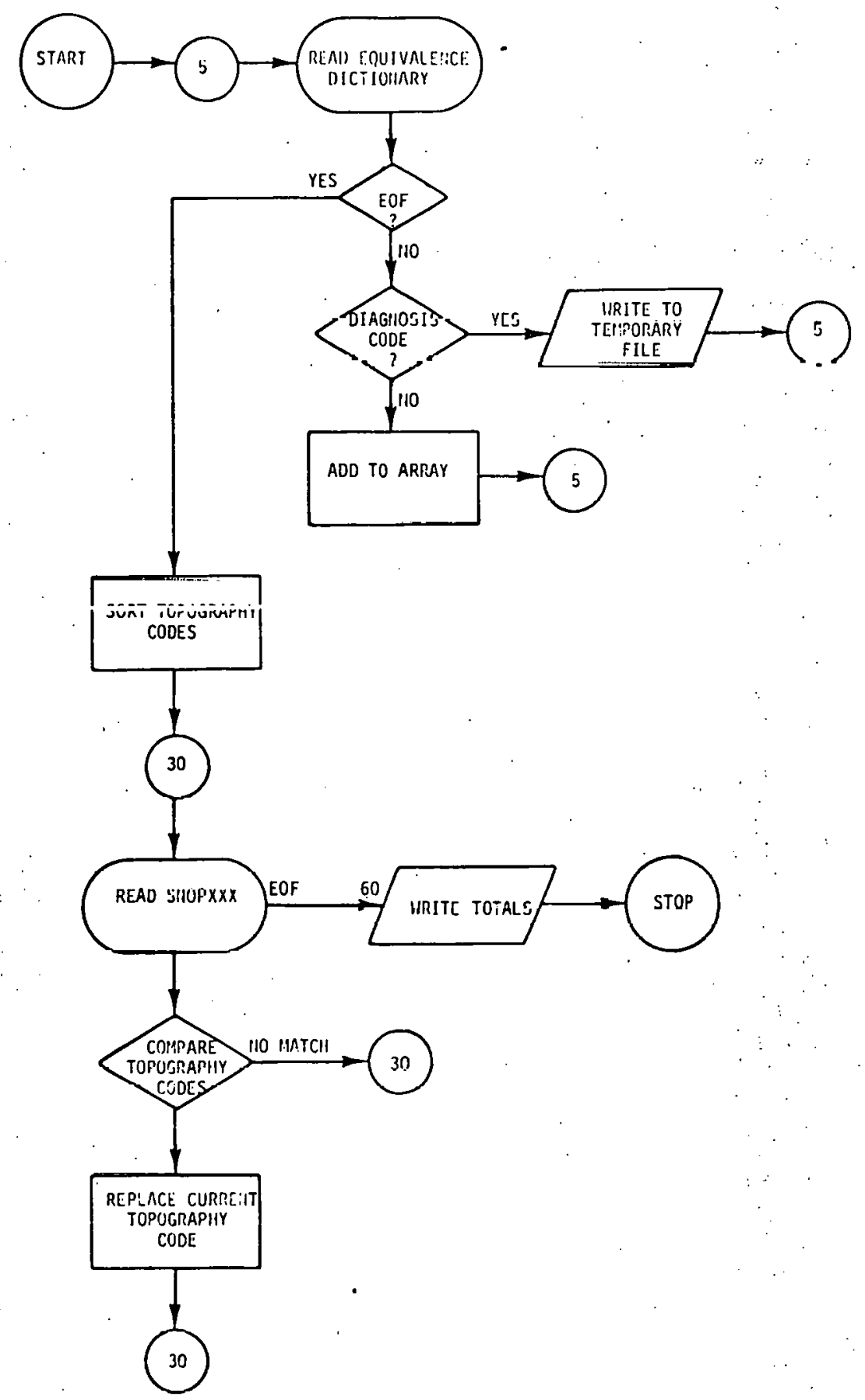

FIGURE 34. SNOP5 Flowchart 


\section{SNOP 6}

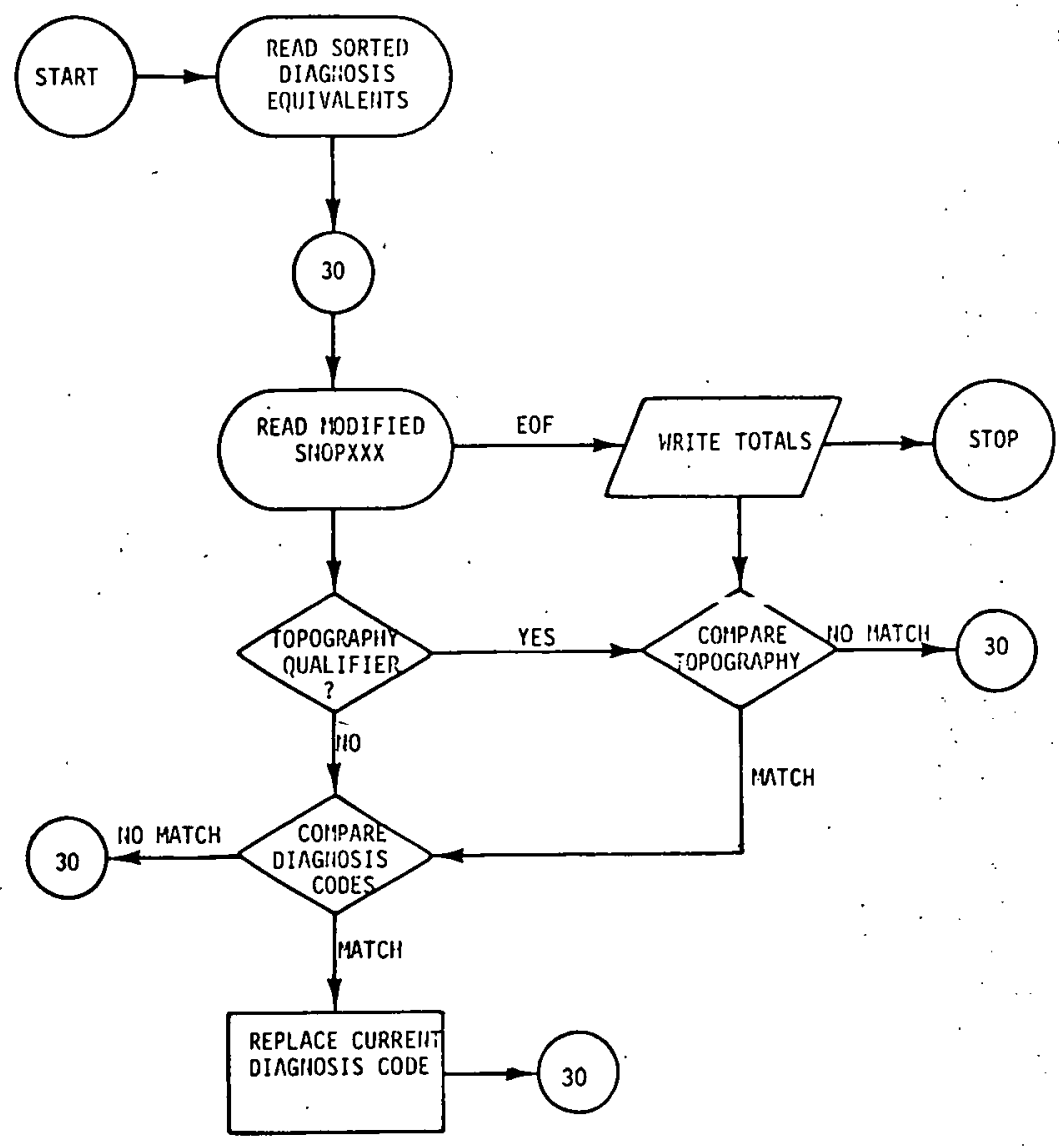

FIGURE 35. SNOP6 Flowchart 


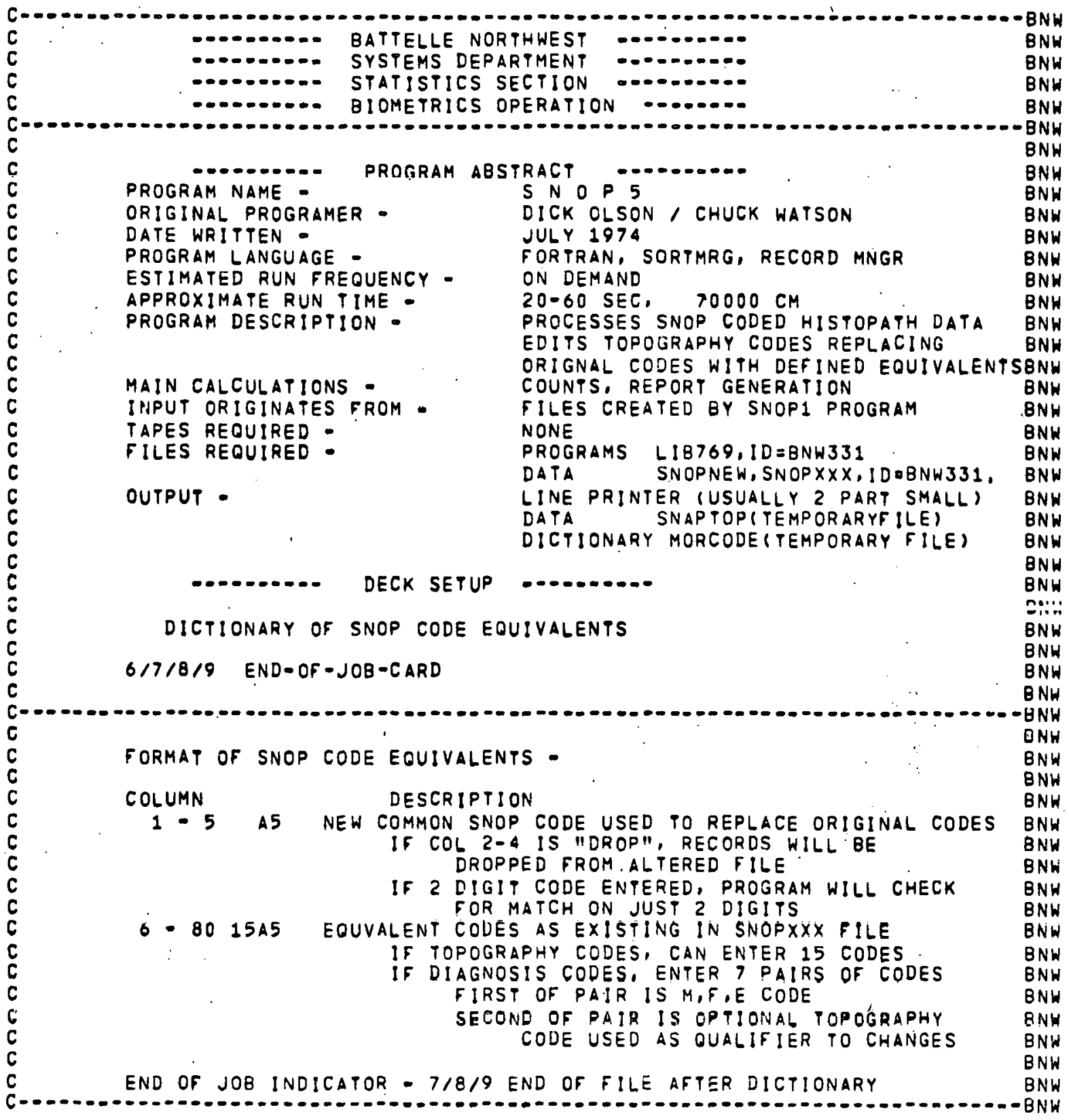

FIGURE 36. SNOP5 Program Abstract 


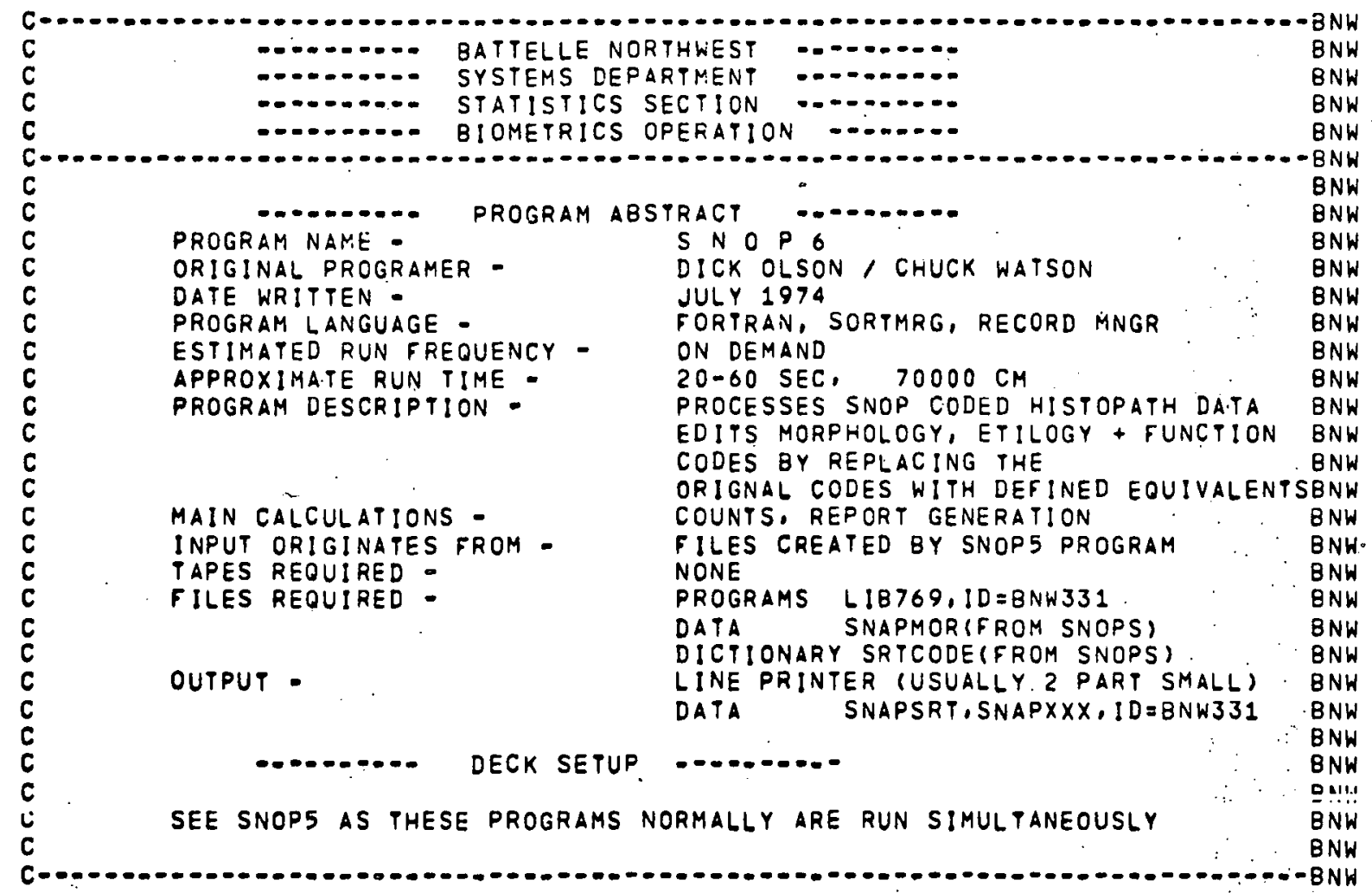

FIGURE 37. SNOP6 Program Abstract 
currently anticipate that these modified files will be purged after the reports have been produced so that the original SNOPXXX and TUMRXXX will be considered the prime data base. 


\section{ACKNOWLEDGMENTS}

The sample data shown in Figures 7 to 15 was obtained as part of a study conducted by Dr. J. E. Ballou. Dr. G. E. Dagle performed the SNOP coding of these observations and contributed many suggestions to increase the usefulness of the SNOP System. The authors appreciate the assistance of Pauline Aldridge, who drew the various run diagrams and flowcharts, and that of Sally Owzarski, who assisted in the final compilation of the report. 
APPENDIX A

A complete FORTRAN listing of the SNOP programs and some example output are contained on this microfiche.

\section{U.S. ATOMIC ENERGY COMMISSION}

RICHLAND OPERATIONS OFFICE

RICHLAND, WASHINGTON 99352

B4-3000-592 (1 1.73) 


\section{DISTRIBUTION}

No. of

Copies

OFFSITE

1

3

14

$\frac{\text { AEC Chicago Patent Group }}{\text { A. A. Churm }}$

AEC Technical Information Center For UC-48 Special Distribution

$$
\begin{aligned}
& \text { N. F. Barr } \\
& \text { W. W. Burr } \\
& \text { C. E. Carter } \\
& \text { C. W. Edington } \\
& \text { R. J. Engelmann } \\
& \text { H. Hollister } \\
& \text { J. L. Liverman } \\
& \text { S. Marks } \\
& \text { M. L. Minthorn } \\
& \text { C. L. Osterberg } \\
& \text { B. O. Stuart } \\
& \text { J. Swinebroad } \\
& \text { B. W. Wachholz } \\
& \text { W. W. Weyzen }
\end{aligned}
$$$$
\text { AEC Division of Biomedical }
$$$$
\text { and Environmental Research }
$$

$3 \quad$ Argonne National Laboratory

$$
\begin{aligned}
& \text { T. F. Fritz } \\
& \text { A. Lindenbaum } \\
& \text { W. P. Norris }
\end{aligned}
$$

$1 \quad \therefore \quad$ E. I: du Pont de Nemours Co. Aiken, Scuth Carolina
No.: of

Copies

OFFSITE

4

Los Alamos Scientific Lab.

R: G. Thomas

G. L. Voelz

J. Prine

L. M. Holl and

5

Lovelace Foundation

R. 0. McClellan

B. Muggenburg

R. K. Jones

F. F. Hahn

S. A. Benjamin

Oak. Ridge National Lab.

T. A: Lincoln

P. Nettesheim

R. Griesemer

J. Storr

C. R. Richmond

C. C. Lushbaugh:

1... Oregon Regional Primate Center J. L. Palotay

8 National Cancer Institute

T. Owen

N. Page.

G.: Gori

R. Squire

U. Saffiotti

M. Sporn

M. Stanton

H: Pettigrew

3 Rocky Flats Division,

Dow Chemical Co.

D. B. Hylton

C. R. Lagerquist

R. W. Bistline 
No. of

Copies

OFFSITE

1

University of California,

Berkeley

$$
\text { P. W. Durbin }
$$

1 University of California,

Davis

M. Goldman

1 University of Connecticut

S. Nielsen

$1 \quad$ University of Georgia

R. L. Farrell

1 Veterans Administration Hospital

East Orange, NJ

0 . Auerbach

3 Washington State University
R. Bortsch
R. Hughes
B. J. Ward

ONSITE

1 AEC/RL Patent Attorney.

R: W. Poteat

1 AEC Richland Operations Office

B. J: Milton

2 Atlantic Richfield Hanford Co.

G. E. Backman

B. J. McMurray

60
No. of

Copies

ONSITE

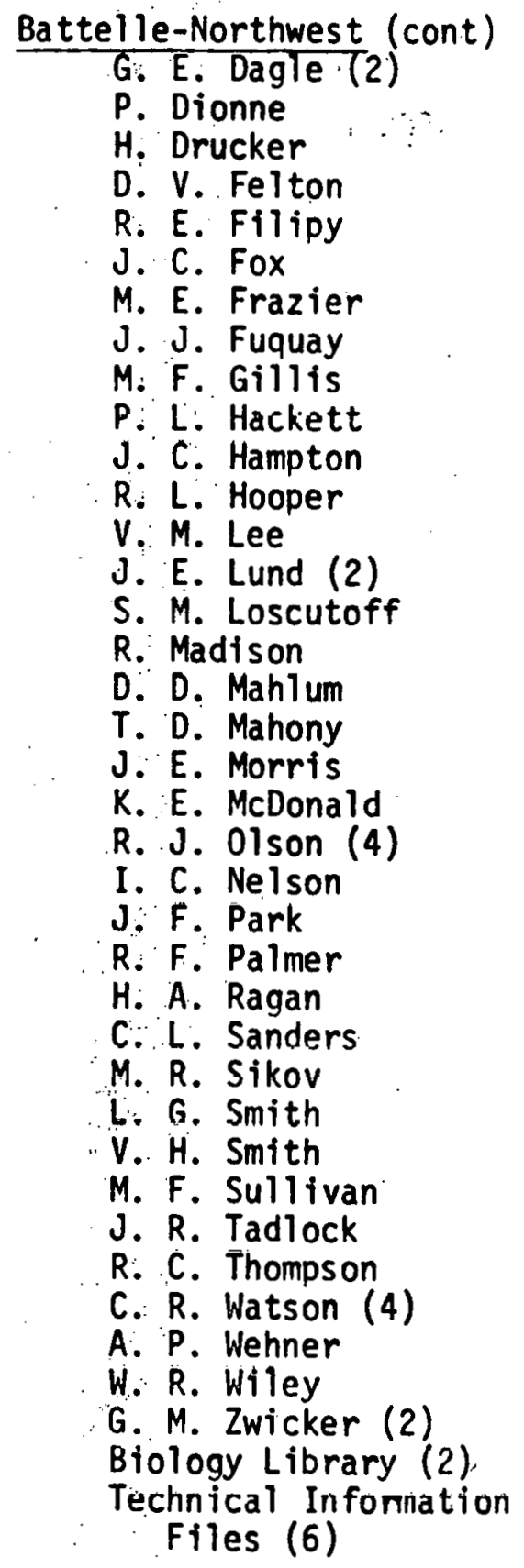




$$
-3-
$$

No. of

Copies

\section{ONSITE}

2 Hanford Environmental Health

Foundation

P. A. Fuqua (2)

1 : Transuranium Registry 